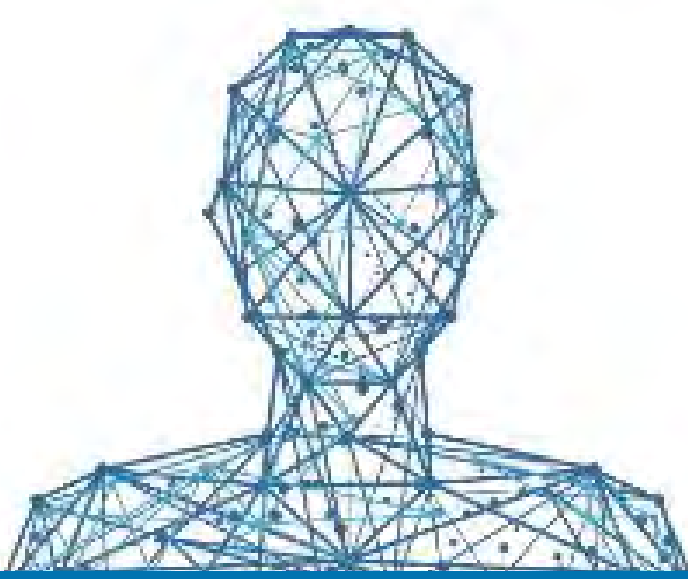

Expandir nosso entendimento da síndrome pós-COVID-19

Relatório de um webinar da OMS,

9 de fevereiro de 2021
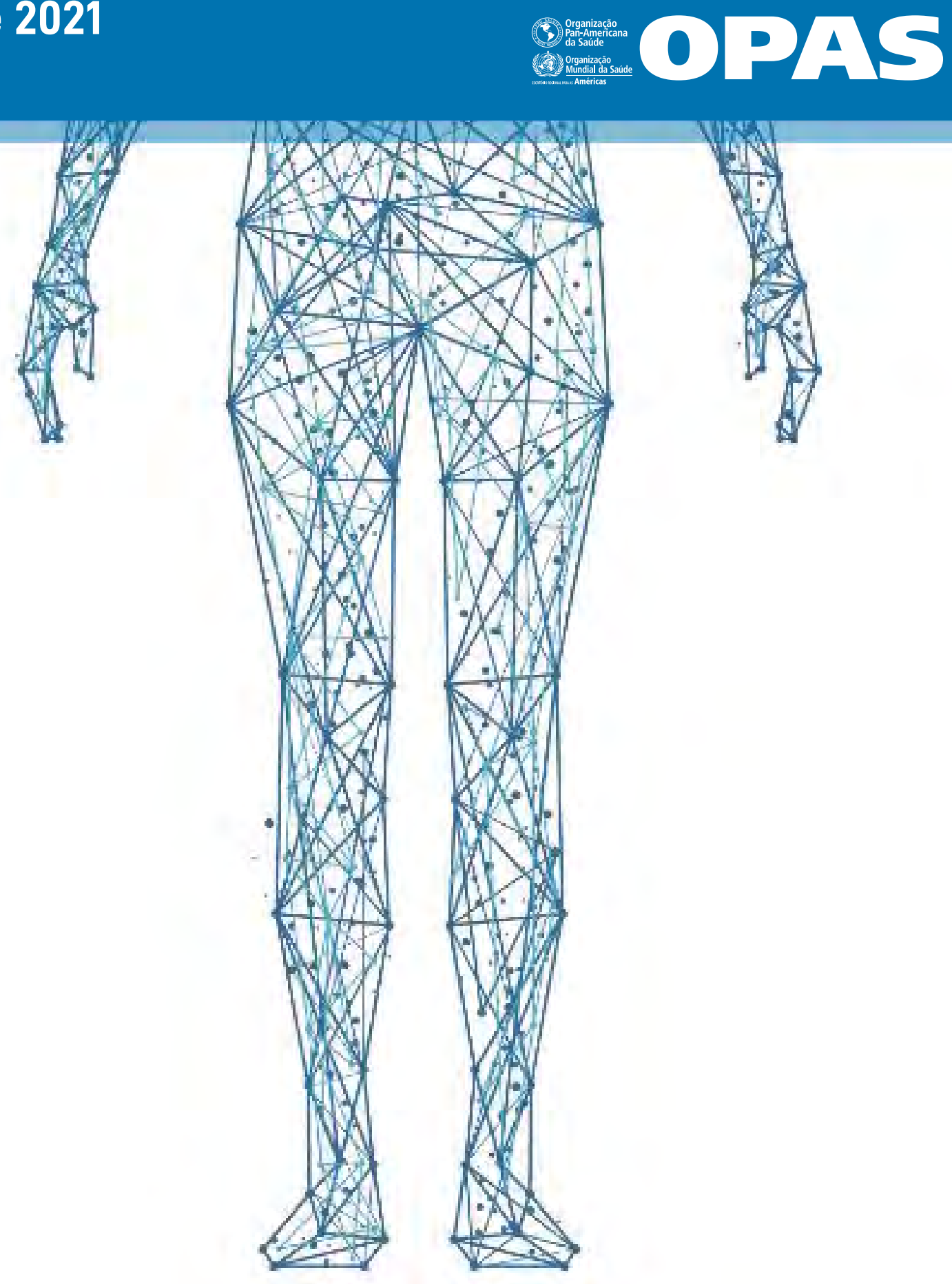


\section{Expandir nosso entendimento da síndrome pós-COVID-19 \\ Relatório de um webinar da OMS, \\ 9 de fevereiro de 2021}


Versão oficial em português da obra original em Inglês

Expanding our understanding of post COVID-19 condition: report of a WHO webinar, 9 February 2021

(C) World Health Organization 2021

ISBN 978-92-4-002503-5 (electronic version)

Expandir nosso entendimento da síndrome pós-COVID-19. Relatório de um webinar da OMS. 9 de fevereiro de 2021

(C) Organização Pan-Americana da Saúde, 2021

ISBN: 978-92-75-72399-9 (pdf)

Alguns direitos reservados. Esta obra está disponível nos termos da licença Atribuição-NãoComercialCompartilhalgual 3.0 OIG de Creative Commons; https://creativecommons.org/licenses/by-nc-sa/3.0/igo/ deed.pt.

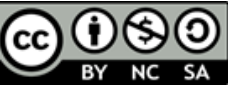

De acordo com os termos desta licença, esta obra pode ser copiada, redistribuída e adaptada para fins não comerciais, desde que a nova obra seja publicada com a mesma licença Creative Commons, ou equivalente, e com a referência bibliográfica adequada, como indicado abaixo. Em nenhuma circunstância deve-se dar a entender que a Organização Pan-Americana da Saúde (OPAS) endossa uma determinada organização, produto ou serviço. O uso do logotipo da OPAS não é autorizado.

Adaptação: No caso de adaptação desta obra, o seguinte termo de isenção de responsabilidade deve ser adicionado à referência bibliográfica sugerida: "Esta é uma adaptação de uma obra original da Organização Pan-Americana da Saúde (OPAS). As perspectivas e opiniões expressadas na adaptação são de responsabilidade exclusiva do(s) autor(es) da adaptação e não têm o endosso da OPAS".

Tradução: No caso de tradução desta obra, o seguinte termo de isenção de responsabilidade deve ser adicionado à referência bibliográfica sugerida: "Esta tradução não foi elaborada pela Organização PanAmericana da Saúde (OPAS). A OPAS não é responsável pelo conteúdo ou rigor desta tradução".

Referência bibliográfica sugerida. Expandir nosso entendimento da síndrome pós-COVID-19. Relatório de um webinar da OMS. 9 de fevereiro de 2021. Brasília, D.F.: Organização Pan-Americana da Saúde; 2021. Licença: CC BY-NC-SA 3.0 IGO. https://doi.org/10.37774/9789275723999.

Dados da catalogação na fonte (CIP). Os dados da CIP estão disponíveis em http://iris.paho.org.

Vendas, direitos e licenças. Para adquirir publicações da OPAS, escrever a sales@paho.org. Para solicitar uso comercial e indagar sobre direitos e licenças, acesse http://www.paho.org/permissions.

Materiais de terceiros. Para a utilização de materiais nesta obra atribuídos a terceiros, como tabelas, figuras ou imagens, cabe ao usuário a responsabilidade de determinar a necessidade de autorização e de obtê-la devidamente do titular dos direitos autorais. O risco de indenização decorrente do uso irregular de qualquer material ou componente da autoria de terceiros recai exclusivamente sobre o usuário.

Termo geral de isenção de responsabilidade. As denominações utilizadas e a maneira de apresentar o material nesta publicação não manifestam nenhuma opinião por parte da OPAS com respeito ao estatuto jurídico de qualquer país, território, cidade ou área, ou de suas autoridades, nem tampouco à demarcação de suas fronteiras ou limites. As linhas pontilhadas e tracejadas nos mapas representam as fronteiras aproximadas para as quais pode ainda não haver acordo definitivo.

A menção a determinadas empresas ou a produtos de certos fabricantes não implica que sejam endossados ou recomendados pela OPAS em detrimento de outros de natureza semelhante não mencionados. Salvo erros ou omissões, os nomes de produtos patenteados são redigidos com a inicial maiúscula.

A OPAS adotou todas as precauções razoáveis para verificar as informações constantes desta publicação. No entanto, o material publicado está sendo distribuído sem nenhum tipo de garantia, seja expressa ou implícita. A responsabilidade pela interpretação e uso do material recai sobre o leitor. Em nenhum caso a OPAS será responsável por prejuízos decorrentes de sua utilização. 


\section{Sumário}

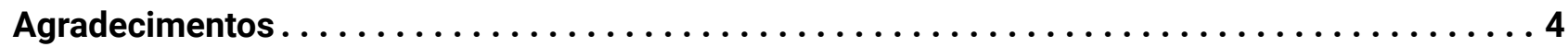

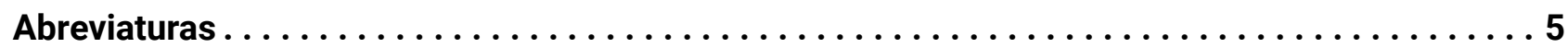

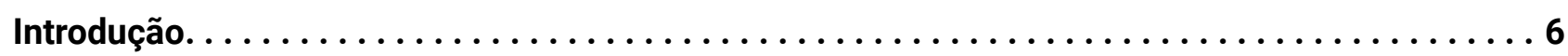

Sessão 1. Síndrome pós-COVID-19: definição do cenário e lições aprendidas . . . . . . . . 7

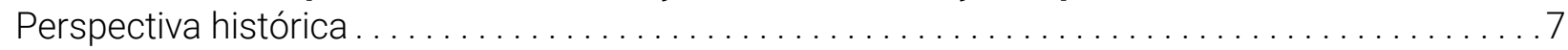

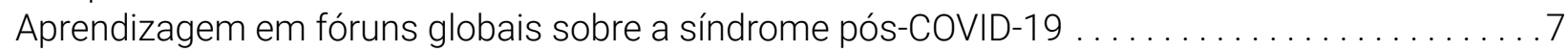

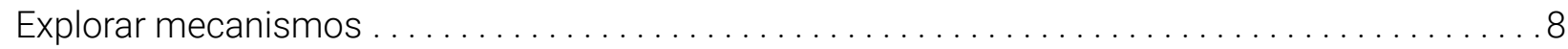

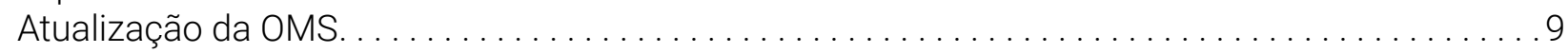

Sessão 2. Observações sobre a síndrome pós-COVID-19: o que sabemos . . . . . . . . . 10

Resultados e recomendações de pesquisa sobre a COVID longa: pesquisa conduzida

pelo paciente. . . . . . . . . . . . . . . . . . . . . . . . . . . . . . . . . . . . . . 10

Consequências da COVID-19 em seis meses, em pacientes que receberam alta hospitalar:

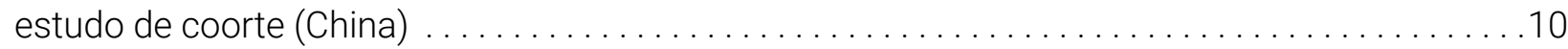

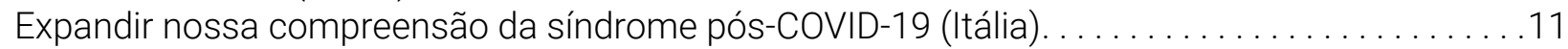

Qualidade de vida e desfechos de longo prazo após hospitalização (Brasil) . . . . . . . . . . . . . 11

Departamento de Biotecnologia do COVID-19 Research Consortium (Índia) . . . . . . . . . . . . 11

Sessão 3. Grupos de trabalho para desenvolvimento da definição de caso clínico e lacunas/ métodos de pesquisa . . . . . . . . . . . . . . . . . . . . 13

Relatório do Grupo de Trabalho 1. Desenvolvimento de uma definição de caso clínico e

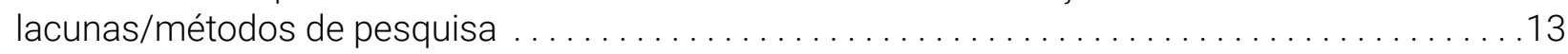

Relatório do Grupo de Trabalho 2. Desenvolvimento de uma definição de caso clínico;

papel do teste diagnóstico . . . . . . . . . . . . . . . . . . . . . . . . . . . . . . . 14

Relatório do Grupo de Trabalho 3. Prevenção, manejo e pesquisa $\ldots \ldots \ldots \ldots \ldots \ldots \ldots \ldots \ldots$

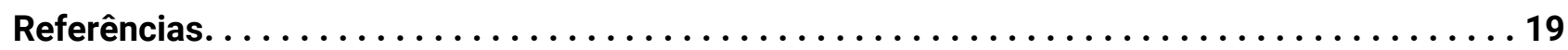

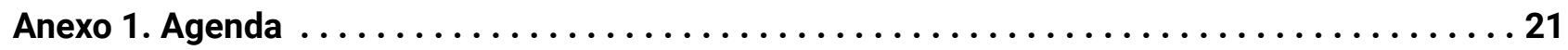

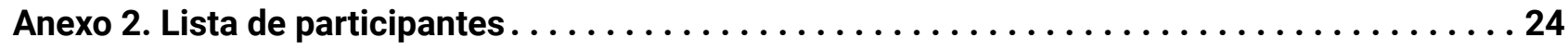

Anexo 3. Desenvolvimento de uma definição de caso clínico para a síndrome pós-COVID-19

(deliberações adicionais do Grupo de Trabalho 1 ) . . . . . . . . . . . . . . . . 28

Anexo 4. Papel do diagnóstico no manejo clínico

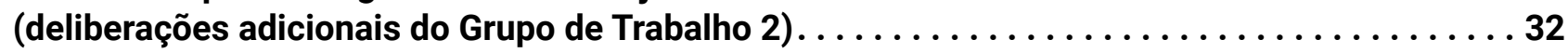

Anexo 5. Prevenção, manejo e pesquisa

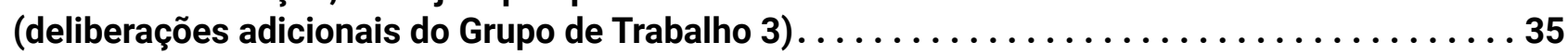




\section{Agradecimentos}

\section{Comitê Diretor da OMS}

Janet Diaz [Líder, Manejo Clínico de Resposta à COVID-19, Health Care Readiness, Genebra, Organização Mundial da Saúde (OMS)]; Cieza Alarcos (Funções Sensoriais, Deficiência e Reabilitação, Genebra, OMS); Carine Alsokhn (Departamento de Saúde e Sistemas de Informação, Genebra, OMS); John Appiah (Região Africana, Líder de Manejo de Casos de COVID-19); Lisa Askie (Líder de Métodos, Normas e Padrões de Qualidade, Genebra, OMS); Silvia Bertagnolio (Divisão de Doenças Transmissíveis e Não Transmissíveis/Equipe Clínica de Resposta à COVID-19, Genebra, OMS); Neerja Chowdhary (Departamento de Saúde Mental e Uso de Substâncias, Genebra, OMS); Tarun Dua (Chefe de Unidade, Saúde do Cérebro, Departamento de Saúde Mental e Uso de Substâncias, Genebra, OMS); Wouter D Groute (Departamento de Manejo de Doenças Não Transmissíveis, Incapacidade, Violência e Lesões, Genebra, OMS); Fahmy Hanna (Departamento de Saúde Mental e Uso de Substâncias, Genebra, OMS); Robert Jakob (Departamento de Saúde e Sistemas de Informação, Genebra, OMS); Chiori Kodama (Região do Mediterrâneo Oriental, Gestão de Riscos Infecciosos); Reveiz Ludovic (Organização Pan-Americana da Saúde, Gestão de Pesquisa em Saúde); Maria Rosario Pérez (Cientista, Unidade de Radiação e Saúde, Genebra, OMS); Mark Perkins (Líder, Laboratório de Resposta à COVID-19, Programa de Emergências de Saúde, Genebra, OMS); Dina Pfeifer (Região Europeia, Gestão de Riscos Infecciosos); Jacobus Preller (Equipe Clínica de Resposta à COVID-19, Genebra, OMS); Pryanka Relan (Departamento de Serviços Integrados de Saúde/Equipe Clínica de Resposta à COVID-19, Genebra, OMS); Nicoline Schiess (Saúde do Cérebro, Departamento de Saúde Mental e Uso de Substâncias, Genebra, OMS); Archana Seahwag (Equipe Clínica de Resposta à COVID-19, Genebra, OMS); Joan B Soriano (Equipe Clínica de Resposta à COVID-19, Genebra, OMS); Maaya Kita Sugai (Departamento de Saúde e Sistemas de Informação, Genebra, OMS); Anna Thorson (Saúde Sexual e Reprodutiva e Pesquisa, Genebra, OMS); Maria Van Kerkhove (Líder Técnico, Resposta à COVID-19, Gestão de Risco Infeccioso, Genebra, OMS).

A OMS agradece aos diversos colaboradores que apoiaram o planejamento desse encontro. Isso inclui os Institutos Nacionais de Saúde dos Estados Unidos, os Centros de Controle e Prevenção de Doenças dos Estados Unidos, o Consórcio Internacional de Infecções Respiratórias Agudas Graves e Emergentes (ISARIC), o GloPID-R e o grupo de pacientes LongSOS. Agradecimentos especiais também para: Nisreen Alwan, Gail Carson, Hannah Davis, Paul Garner, Andrea Lerner, Natalie McDermott e Pierro Olliaro.

Agradecemos também a todos os presidentes, palestrantes e, o mais importante, aos membros do painel por suas excelentes contribuições durante o encontro. Ver Anexos 1 e 2 para as listas completas de palestrantes e participantes do painel. 


\section{Abreviaturas}

ACE-2 enzima conversora de angiotensina 2

IA inteligência artificial

SDRA síndrome de desconforto respiratório agudo

PAC pneumonia adquirida na comunidade

SFC síndrome da fadiga crônica

COVID-19 doença causada pelo coronavírus 2019

CRF formulário de relato de caso

DLCO capacidade de difusão de monóxido de carbono

EHR registros eletrônicos de saúde

GI gastrointestinal

GloPID-R Colaboração em Pesquisa Global para a Prevenção de Doenças Infecciosas

CG clínico geral

IASC Comitê Permanente Interagências

UTI unidade de terapia intensiva

ISARIC Consórcio Internacional de Infecções Respiratórias Agudas Graves e Emergentes

PBMR países de baixa e média renda

EM encefalomielite mialgica

NIH/NIAID National Institutes of Health/National Institute of Allergy and Infectious Diseases

SPTI síndrome pós-terapia intensiva

TEPT transtorno de estresse pós-traumático

ECR estudo clínico randomizado

SARS-CoV-2 síndrome respiratória aguda grave do coronavírus-2

DSIE doença sistêmica de intolerância ao esforço

OMS Organização Mundial da Saúde

TC6M teste de caminhada de seis minutosO 


\section{Introdução}

Durante a primeira onda da pandemia da COVID-19, os pesquisadores já começaram a montar estudos de coorte longitudinais para avaliar as sequelas da COVID-19. Em agosto de 2020, a Organização Mundial da Saúde (OMS) reuniu-se com pacientes do grupo LongCovidSOS e defendeu a necessidade de reconhecimento, pesquisa e reabilitação. Em setembro de 2020, a OMS havia estabelecido o código CID-10 para a síndrome pós-COVID-19. Em janeiro de 2021, a OMS publicou sua orientação inicial sobre o manejo clínico de pacientes após a doença aguda.

Posteriormente, houve aumento no número e no escopo das atividades de pesquisa da síndrome pós-COVID-19 por agências de saúde pública, acadêmicos, grupos de pesquisa liderados por pacientes e outras partes interessadas. No entanto, a falta de consenso sobre a definição de caso clínico e a compreensão limitada da caracterização clínica durante o período de recuperação e a fisiopatologia associada limitaram o progresso no diagnóstico, no tratamento e no manejo.

Com o objetivo de avançar nesse campo reunindo partes interessadas de todo o mundo, a OMS organizou uma série de webinars com os seguintes objetivos específicos:

- prioridades de ação em reconhecimento, pesquisa e reabilitação;

- apresentação de conhecimentos científicos atualizados sobre a síndrome pós-COVID-19;

- enriquecimento da discussão por meio de grupos de trabalho com painéis de especialistas.

Em 9 de fevereiro de 2021, um primeiro webinar intitulado "Expandir nosso entendimento da síndrome pós-COVID-19" foi realizado sob os auspícios da OMS e em consulta com o Consórcio Internacional de Infecção Respiratória Aguda Grave e Emergente (ISARIC), com a Colaboração em Pesquisa Global para a Prevenção de Doenças Infecciosas (GloPID-R), com os Institutos Nacionais de Saúde/Instituto Nacional de Alergia e Doenças Infecciosas (NIH/NIAID), com o LongCovidSOS e com os representantes dos pacientes. A reunião ocorreu ao longo de um período de 5 horas, dividido nas três sessões a seguir:

- Sessão 1. Síndrome pós-COVID-19: definição do cenário e lições aprendidas

- Sessão 2. Observações sobre a síndrome pós-COVID-19: o que sabemos

- Sessão 3. Grupos de trabalho para desenvolvimento da definição de casos clínicos e lacunas/ métodos de pesquisa.

Para esse webinar inicial, os participantes foram convidados por meio de várias redes clínicas, redes de pesquisa e centros colaboradores. Mais de 700 participantes compareceram. Os palestrantes foram selecionados para apresentar os resultados de grandes estudos de coorte publicados que foram encontrados em pesquisas sistemáticas da literatura e por meio de outras fontes relevantes. As declarações de conflitos de interesse foram coletadas, avaliadas e gerenciadas pela unidade técnica responsável, de acordo com os procedimentos padrão da OMS para todos os palestrantes. Todos os palestrantes foram avaliados como não tendo conflitos de interesses financeiros.

Os grupos de trabalho foram constituídos com painéis multidisciplinares para aprofundar questões predefinidas. O comitê gestor da OMS foi responsável por definir a agenda, selecionar os palestrantes e formular as questões do grupo de trabalho. Os desfechos de cada grupo de trabalho agora estão sendo usados para orientar um processo Delphi, que será usado para esboçar uma descrição de caso clínico para a síndrome pós-COVID-19. 


\section{Sessão 1. Síndrome pós-COVID-19: definição do cenário e lições aprendidas}

Esta sessão contou com seis palestrantes que foram escolhidos para apresentar informações que definiram o cenário. Haverá sumários de alto nível, mas para ver as apresentações completas, consulte o nosso site. (1)

\section{Perspectiva histórica}

As duas primeiras apresentações enfocaram o que foi aprendido com outras doenças: "Aprender com infecções virais anteriores: gripe, SARS, MERS, zika" e "Aprender com doenças críticas anteriores: síndrome pós-terapia intensiva".

O Dr. Carlos A Pardo descreveu os vários surtos de doenças infecciosas dos últimos dois séculos, como as pandemias de gripe de 1918 (H1N1), 1957 (H2N2), 1968 (H3N2), 2009 (H1N1), bem como outros surtos virais de vírus emergentes como a doença causada pelos vírus ebola (2014), chikungunya (2013-2015), zika (2015-2016), SARS (2002-2004) e MERS (2012); todos eles precedendo essa pandemia atual do SARS-CoV-2 (2019). As complicações neurológicas foram bem descritas. O Dr. Pardo citou um artigo do Lancet publicado em 1891, que relatava a pandemia de gripe e descrevia várias manifestações neurológicas (ou seja, neuralgia, exaustão nervosa, inércia) e o excepcionalmente "baixo nível de vitalidade humana",(2) isso foi então seguido por relatos dos efeitos neurológicos da pandemia de gripe de 1918 e, mais recentemente, das complicações neurológicas associadas ao vírus zika (ou seja, síndrome de Guillain-Barré, encefalite e neurite óptica etc.) e ao vírus chikungunya (ou seja, deficiência na alta hospitalar). (3) Ele concluiu dizendo que a COVID-19 claramente apresentava manifestações sistêmicas e neurológicas durante a fase aguda e que também podiam durar até as fases de convalescença e recuperação, levando à síndrome pós-COVID-19.

O professor Dale Needham fez uma apresentação sobre a síndrome pós-terapia intensiva (SPTI), uma síndrome descrita pela Society of Critical Care Medicine para aumentar a conscientização sobre sintomas e deficiências funcionais de longa duração vivenciadas pelos sobreviventes de doenças críticas. (4) SPTI é descrito como deficiências novas ou agravantes em um ou mais dos três domínios principais: saúde física, cognitiva (5) e mental, (6) que surgem após tratamento em unidade de terapia intensiva (UTI) e persistem além da hospitalização para cuidados agudos. Vale a pena notar que esse termo pode ser aplicado a um sobrevivente ou a um membro da família. Com o tempo, outros sintomas também foram observados, incluindo fadiga (7) e deficiências que afetam a qualidade de vida $(8,9)$ e o emprego. $(10,11)$ O professor Needham descreveu o trabalho no conjunto de desfechos básicos da SPTI, que é patrocinado e financiado pelos Institutos Nacionais de Saúde dos Estados Unidos $(\mathrm{NIH})$ e visa melhorar a pesquisa de desfechos de longo prazo da insuficiência respiratória aguda em todos os estudos sobre sobrevida em UTI. (12-14)

Esse conjunto de desfechos básicos está sendo criado por meio de um processo de consenso internacional modificado da Delphi com membros do painel de mais de 16 países em seis continentes, incluindo aproximadamente $25 \%$ de pacientes ou familiares. (15) Essa mesma metodologia pode ser usada para desenvolver um conjunto de desfechos básicos para a síndrome pós-COVID-19.

\section{Aprendizagem em fóruns globais sobre a síndrome pós-COVID-19}

As duas apresentações seguintes enfocaram os aprendizados das duas reuniões globais mais recentes sobre esse tópico convocadas pelo $\mathrm{NIH}$ e pelo grupo de apoio ISARIC-GloPID-R-Long COVID. 
A Dra. Andrea Lerner apresentou os aprendizados do workshop do NIH sobre sequelas pós-agudas da COVID-19, realizado de 3 a 4 de dezembro de 2020. 0 objetivo desse workshop foi resumir o conhecimento existente e identificar as principais questões e lacunas de conhecimento nessa área. As principais descobertas destacadas foram relatos comuns de deficiência cognitiva e de problemas de saúde mental, com representação desproporcional nos Estados Unidos entre as minorias raciais e étnicas e aqueles com falta de cobertura de saúde. Os fenótipos são numerosos e a resposta imunológica pode desempenhar um papel importante. As lacunas foram resumidas: necessidade de vocabulário/terminologia comum; definição da epidemiologia; descrição dos fenótipos e histórias naturais; identificação de fatores de risco; impacto da vacinação e terapêutica. Os anais do relatório ainda não foram publicados. O NIH emitiu um Comunicado de Intenção de Publicar Anúncios de Oportunidades de Pesquisa para o estudo sobre COVID-19 pós-aguda.

A Dra. Gail Carson apresentou as aprendizagens do fórum sobre COVID longa do grupo de apoio ISARIC-GloPID-R-Long COVID, que foi realizado de 9 a 10 de dezembro de 2020. Esse encontro - que reuniu pacientes, pesquisadores e financiadores, com o tema "Nada sobre nós sem nós" - refletiu sobre a abordagem conduzida pelo paciente para priorização da agenda. As seguintes prioridades foram destacadas: causa da doença; como recuperar; quantos outros são afetados; qual é a definição; quais são as características clínicas; quais são as manifestações em crianças e outras subpopulações (ou seja, pessoas com HIV); impacto na saúde mental e como intervir. O Dr. Carson levantou preocupações sobre a falta de estudos sobre a COVID longa, o foco em pacientes hospitalizados e a falta de estudos em crianças e em países de baixa e média renda (PBMRs). Suas descobertas foram publicadas no Lancet Infectious Disease em 4 de fevereiro de 2021, com uma proposta esquemática para um roteiro de pesquisa abrangente e inclusivo, envolvendo pesquisa clínica e sistemas de saúde centrados na perspectiva do paciente. (16)

\section{Explorar mecanismos}

Houve uma apresentação para reunir o que se pensa atualmente: "Imunologia e fisiopatologia da COVID longa - o que não sabemos e o que precisamos saber".

O professor Daniel Altmann apresentou as novas clínicas para COVID longa dentro do National Health Service no Reino Unido da Grã-Bretanha e Irlanda do Norte, e a necessidade de uma abordagem multidisciplinar, holística e coordenada; bem como a necessidade de critérios harmonizados para um diagnóstico de trabalho a fim de facilitar o acesso a cuidados adequados. Ressaltando que, para oferecer tratamento racional, é preciso entender os mecanismos. (17)

Foram propostas algumas hipóteses de trabalho para as investigações atuais: dano residual ao tecido infectado positivo para enzima conversora de angiotensina 2 (ACE 2); estimulação imunológica contínua proveniente de reservatórios de infecção persistente; perturbação crônica de subconjuntos imunes após infecção aguda; e ativação de uma resposta autoimune após infecção aguda. Além disso, outras observações importantes incluíram que até mesmo os casos assintomáticos podem ter anormalidades pulmonares radiográficas. As células positivas para ACE-2 (pulmão, coração, rim e outras) podem ser locais potencialmente propensos a fibrose. Um recente estudo de ressonância magnética, o COVERSCAN, com mais de 200 indivíduos com COVID longa, revelou o envolvimento de múltiplos órgãos, afetando especialmente o coração e os pulmões. (18) Foram levantadas possíveis semelhanças entre a resposta imune associada à COVID-19 e as observadas no vírus Epstein-Barr, na doença do vírus ebola (19) e no vírus chikungunya. (20)

Por fim, o professor Altman concluiu que esse novo grupo de pacientes pode representar um fardo significativo para o sistema de saúde, apenas pelos números absolutos, e alertou que não sabemos quanto tempo isso pode durar. Foi feito uma conclamação ao envolvimento dos decisores políticos e financiadores de investigação para que sejam tomadas medidas a fim de encontrar respostas. 


\section{Atualização da OMS}

Essa primeira sessão terminou com uma apresentação da Dra. Janet Diaz, que atualizou o público presente em relação às atividades relacionadas à síndrome pós-COVID-19. A partir de agosto de 2020, a OMS se reuniu com representantes do grupo LongCovidSOS e defendeu as prioridades de reconhecimento, pesquisa e reabilitação. Em setembro de 2020, a unidade de Classificação e Terminologias, que vinha ativando progressivamente os códigos de emergência para COVID-19 no CID-10 e CID-11, após consulta aos comitês e grupos de referência relevantes, publicou os códigos pós-COVID-19.

Uma ênfase numa abordagem abrangente e multidisciplinar para o cuidado de pacientes com COVID-19 - que já era a marca registrada da via de atendimento da COVID-19 - foi agora estendida a indivíduos após a doença aguda e incorporada ao novo capítulo do Manejo clínico da COVID-19: orientação dinâmica, da OMS, intitulado, "Cuidado de pacientes após doença aguda". As contribuições de várias disciplinas, como serviços de reabilitação, saúde cerebral e saúde mental, foram essenciais nessa atualização.

Além disso, foi reconhecido que a saúde mental é um componente abrangente e integral de todas as respostas de emergência de saúde pública, e que a OMS, em colaboração com os parceiros do Comitê Permanente Interagências (IASC), envolveu-se no desenvolvimento de ferramentas operacionais e de orientações para saúde mental e apoio psicológico.

Por fim, a OMS anunciou o lançamento do Formulário de registro de caso pós-COVID-19 (CRF-4), uma ferramenta para coleta de dados padronizados após doença aguda, que tem três módulos abrangentes para apoiar a coleta de dados padronizados globalmente, para ser usado como parte dos registros ou ensaios clínicos, para facilitar a agregação de dados e a meta-análise. 


\section{Sessão 2. Observações sobre a síndrome pós-COVID-19: o que sabemos}

Esta segunda sessão deu espaço para que vários pesquisadores apresentassem suas descobertas sobre a síndrome pós-COVID-19. Todas as apresentações podem ser encontradas no site. (1)

\section{Resultados e recomendações de pesquisa sobre a COVID longa: pesquisa conduzida pelo paciente}

A Sra. Hannah Davis, do Patient-Led Research Collaborative, que foi estabelecido em parceria com a University College London, apresentou os resultados de sua segunda enquete, que incluiu 3.762 entrevistados de 56 países e examinou 205 sintomas, seu impacto no trabalho e na vida, teste de anticorpos e diagnósticos ao longo de um período de sete meses. (21) A maioria dos entrevistados nunca foi hospitalizada - 92\% (3.445 em 3.762) - e 18\% (668 em 3.762) eram profissionais de saúde.

Os resultados mostraram que os sintomas mais prováveis de persistir em seis meses eram sistêmicos e neurológicos, e que os sintomas mais comuns eram: fadiga; disfunção cognitiva; mal-estar pós-esforço (piora dos sintomas mesmo após pequenos esforços); sintomas sensóriomotores (tonturas, tremores, parestesia); dor de cabeça; problemas de memória; insônia; palpitações; falta de ar; tontura; problemas de fala; dores nas articulações e aperto no peito. Digno de nota, os sintomas respiratórios não foram comumente relatados, mas 93\% (3.505 de 3.762) dos entrevistados ainda apresentavam sintomas em uma média de 144 dias de acompanhamento, e apenas 7\% (257 de 3.762) se recuperaram, com média de 91 dias para a recuperação. Os entrevistados que não se recuperaram até o mês 7 apresentaram em média 14 sintomas.

Além disso, -entre as pessoas com "névoa cerebral", 67,5\% (2.169 de 3.214) necessitaram reduzir as horas de trabalho ou ficaram impossibilitadas de trabalhar devido à doença; 86,2\% (2.853 de 3.310) relataram que isso afetou seu trabalho de forma leve a severa. Vale a pena notar que não houve associação entre disfunção cognitiva ou perda de memória e idade.

Em conclusão, a Sra. Davis descreveu várias questões prioritárias de pesquisa para entender melhor a COVID longa: tempo de conversão sorológica; papel da persistência viral; variações na resposta imune; etiologia do mal-estar pós-esforço e recaídas; e o papel de investigações apropriadas que incluam exames de imagens, respostas imunes subjacentes, perfil metabólico, hipometabolismo cerebral e hipoperfusão e funcionamento alterado das células T e B. Além disso, foi feito uma conclamação para a lembrança de "fazer as perguntas certas" e a necessidade de incluir uma seleção abrangente de pacientes nos estudos de pesquisa.

As apresentações restantes enfocaram as experiências dos países em estudos de coorte pós-COVID-19.

\section{Consequências da COVID-19 em seis meses, em pacientes que receberam alta hospitalar: estudo de coorte - China}

O Dr. Bin Cao apresentou um estudo de coorte $(n=1.733)$ sobre as consequências da COVID-19 ao longo de seis meses em pacientes que receberam alta de um hospital em Wuhan, China. A avaliação de acompanhamento incluiu: pesquisa de sintomas, exame físico, teste padronizado de limitações funcionais e relacionadas à saúde (ou seja, escala de dispneia MRC, EQ-5D-5L, EQ-VAS) e outros testes de diagnóstico [ou seja, exames de sangue, TC de tórax de alta resolução, teste de caminhada de 6 minutos (TC6M), teste de função pulmonar e ultrassonografia de membros inferiores e abdômen]. Os resultados dignos de nota apresentados incluíram: idade mediana de 57 anos, acompanhamento médio de 186 dias a partir do início dos sintomas e mortalidade de 1,3\%. 
Os sintomas mais comumente relatados foram fadiga/fraqueza muscular 63\% (2.370 em 3.762), dificuldades para dormir 26\% (978 em 3.762) e ansiedade/depressão 23\% (865 em 3.762). Porém, menos de 10\% (376 de 3.762) relataram problemas de mobilidade, nas atividades habituais ou nos cuidados pessoais. A análise de regressão multivariada encontrou associação entre a gravidade da hospitalização e anormalidades nos testes de difusão pulmonar, exames de imagem de tórax e ansiedade/depressão. As mulheres estavam em maior risco de anormalidades pulmonares, ansiedade e fadiga/fraqueza muscular. Em conclusão, os pesquisadores sugeriram que esta pode ser a principal população-alvo para intervenções de recuperação em longo prazo. (22)

\section{Expandir nossa compreensão da síndrome pós-COVID-19 - Itália}

O Dr. Marco Rizzi apresentou os resultados do Projeto Bergamo Itália, (23) um grande estudo de coorte de acompanhamento $(n=1.536)$ que começou logo após a primeira onda da pandemia e incluiu o acompanhamento de pacientes de alto risco na alta para clínicas dedicadas à COVID-19. Essas clínicas forneceram um modelo de atendimento multidisciplinar e coleta de dados padronizada, incluindo exames laboratoriais, exames de imagem do tórax, testes de função pulmonar e avaliações padrão das necessidades psicossociais e de reabilitação. A análise preliminar revelou idade média de 59 anos, e na primeira consulta pós-alta os seguintes sintomas foram comumente relatados: dispneia (509/1.524, 33\%), capacidade reduzida de difusão de monóxido de carbono (DLCO) (346/1.289, 28\%) e transtorno de estresse pós-traumático (TEPT) (477/1.467, 32\%). O palestrante concluiu que os pacientes com síndrome pós-COVID-19 necessitam de modelos de atendimento mais seletivos e com melhores recursos para garantir a viabilidade e a sustentabilidade. Uma análise mais detalhada está em andamento e a colaboração global é bem-vinda.

Subsequentemente, o Dr Simone Piva apresentou o acompanhamento de uma pequena coorte de sobreviventes de UTI aos 3 e 6 meses $(n=93)$ e o relatório dessa coorte, cuja idade média era de 62 anos, nos seguintes domínios: funções pulmonares, físicas e cognitivas; e saúde mental e qualidade de vida, por meio de escalas padronizadas. Os resultados dignos de nota incluíram: capacidade de difusão moderadamente reduzida (47\%); dinamometria da mão dominante levemente reduzida (40\%); escore anormal de fadiga (FSS> 36) (36\%); comprometimento cognitivo leve (18\%-26\%); ao passo que os escores de saúde mental para depressão, ansiedade e TEPT estavam em sua maioria normais.

\section{Qualidade de vida e desfechos de longo prazo após hospitalização - Brasil}

O Dr. Regis Goulart Rosa apresentou os desfechos de um estudo de coorte prospectivo de pacientes adultos hospitalizados $(n=931)$ acompanhados por um período de um ano. Os pacientes foram recrutados em 55 centros do Brasil, que participaram de cinco ensaios clínicos randomizados (ECRs) que envolveram pacientes com gravidade variável (leve a crítica). O desfecho primário era a qualidade de vida relacionada à saúde (EQ5D3L), e os desfechos secundários incluíram mortalidade por todas as causas, reinternações, retorno ao trabalho ou estudo, estado físico funcional, necessidade de suporte ventilatório de longo prazo, sintomas de ansiedade e depressão e sintomas de TEPT.

Os desfechos preliminares mostraram que, entre os sobreviventes de hospitalização devido à COVID-19, a mortalidade foi elevada durante os meses após a alta; as reinternações eram comuns; o fardo das deficiências físicas e mentais foi alto; e a necessidade de ventilação mecânica durante a hospitalização pareceu ser um preditor de desfechos ruins em longo prazo.

\section{Departamento de Biotecnologia do COVID-19 Research Consortium - Índia}

A professora Shinjini Bhatnagar apresentou os resultados preliminares de um estudo de coorte observacional prospectivo que acompanhou pacientes com COVID-19 hospitalizados $(n=3.832)$ 
após a alta e coletou dados demográficos, histórico de contatos, sintomatologia, comorbidades, medicamentos, exposição, histórico de viagens, hospitalizações e tratamentos. Na consulta de 6 a 10 semanas, 5\% (165 de 3.320) dos pacientes apresentavam um ou mais sintomas. Entre os 85 pacientes com idade mediana de 65 anos avaliados aos 6 meses, foi relatada fadiga em 6\% (5 de 85 pacientes). Notou-se a preparação em andamento para a realização de estudos observacionais em outras populações frágeis, incluindo gestantes, crianças, adolescentes e recém-nascidos. 0 palestrante concluiu que é necessário definir as características comuns, a duração da doença associada aos clusters de sintomas, a descrição de caso clínico e agora os dados harmonizados. 


\section{Sessão 3. Grupos de trabalho para desenvolvimento da definição de caso clínico e lacunas/métodos de pesquisa}

\section{Relatório do Grupo de Trabalho 1. Desenvolvimento de uma definição de caso clínico e lacunas/métodos de pesquisa}

Coencarregados: Dra. Margaret Herridge, Dr. Tarun Dua. Ver Anexo 2 para todos os membros do painel.

\section{Resumo}

Ficou evidente que nem todos os pacientes com COVID-19 apresentam resolução completa dos sintomas, e alguns pacientes relatam o surgimento de novos sintomas ao longo do tempo. As variações podem representar expressões heterogêneas da doença determinadas pela biologia/ genética do hospedeiro e/ou processos de doença distintos. No entanto, as diferenças também podem ser explicadas pelo uso de métodos diferentes para abordagem diagnóstica e pela precisão da detecção de sintomas.

\section{Problemas e oportunidades}

Os participantes destacaram a baixa qualidade de alguns relatórios e suas diferenças no desenho e métodos dos estudos, o que complicará as estimativas de agrupamento. Tem havido falta de pesquisas harmonizadas para determinar fenótipos distintos pós-COVID-19 e a variabilidade no espectro dos complexos de sintomas em órgãos-alvo e sua gravidade. É ainda mais complicado delinear e validar fenótipos distintos por meio de acesso variável aos diagnósticos. Consequentemente, nem sempre é possível obter evidências laboratoriais de infecção anterior por SARS-CoV-2. A fisiopatologia das sequelas pós-COVID-19 é mal compreendida e não há associação robusta entre a gravidade da doença aguda e os sintomas subsequentes.

\section{Caminho proposto a seguir}

O esquema deve captar simultaneamente os clusters de sintomas por sistema de órgãos; identificar a gravidade das manifestações e a expressão diferencial em diversas populações de pacientes (incluindo adultos, crianças, recém-nascidos, gestantes e lactantes e grupos socialmente desfavorecidos); determinar o risco em potencial ou os fatores de proteção associados ao desenvolvimento da síndrome pós-COVID-19; determinar a associação entre a gravidade da infecção inicial por COVID-19 e o tratamento em diferentes países/sistemas de saúde; e compreender as respostas dinâmicas e variáveis do hospedeiro e sua ligação com os desfechos, incluindo deficiência funcional e cognitiva, transtornos do humor e qualidade de vida relacionada à saúde.

Os padrões fenotípicos clínicos identificados devem ser validados por meio de uma avaliação detalhada e da compreensão da fisiopatologia subjacente. Os achados de pesquisa devem ser avaliados quanto à qualidade, incluindo a origem dos casos, a qualidade e intensidade da avaliação diagnóstica e a precisão da investigação dos achados recém-diagnosticados durante o acompanhamento. Por fim, a definição de caso deve servir a um papel epidemiológico para facilitar a vigilância de casos e também promover o manejo de casos (ver mais informações sobre vigilância em https://blogs.bmj.com/bmj/2021/02/03/nisreen-alwan-we-must-pay-more-attention-to-covid-19morbidity-in-the-second-year-of-the-pandemic/). 0 foco no paciente deve estar entre as mais altas prioridades.

Existe um consenso emergente de que uma abordagem gradual deve ser adotada para alinhar a descrição, a nomenclatura, a compreensão, a prevenção, o manejo e a pesquisa dessa doença (que 
pode ser um grupo de doenças) e incluir uma descrição granular inicial dos sintomas e desfechos, incluindo os domínios descritos anteriormente, com a subsequente identificação de fenótipos variáveis.

Uma definição de caso inicial pode ser ajustada posteriormente - antes que todos os dados necessários estejam disponíveis. Se a infecção inicial for definida/diagnosticada clinicamente retrospectivamente ou por confirmação laboratorial - pode se considerar que, se um paciente não se recuperar do estado inicial de saúde, é razoável fazer a suposição de síndrome pós-COVID-19. Um roteiro deve identificar as lacunas de pesquisa, alinhar a metodologia de pesquisa, promover a colaboração e priorizar o foco no paciente ao abordar cada tema.

Ver Anexo 3 para deliberações adicionais do Grupo de Trabalho 1.

\section{Relatório do Grupo de Trabalho 2. Desenvolvimento de uma definição de caso clínico; papel do teste diagnóstico}

Coencarregados: Professor John Marshall, Dra. Maria del Rosario Pérez. Ver Anexo 2 para todos os membros do painel.

\section{Resumo}

A literatura emergente sugere que a síndrome pós-COVID-19 é uma doença multissistêmica com manifestações dominantes que diferem entre os pacientes e em cada paciente ao longo do tempo. Portanto, é importante compreender como padronizar os testes diagnósticos de modo a orientar o atendimento clínico e o prognóstico para os pacientes, profissionais de saúde e sistemas de saúde. A gama de sintomas inclui fadiga, mal-estar pós-esforço, sintomas sensório-motores e névoa cerebral como sintomas comumente sobrepostos, mas até 150 sintomas diferentes foram associados à síndrome até o momento. O teste diagnóstico pode fornecer informações aos médicos e pacientes sobre as condições agudas e crônicas no contexto de um fenótipo, síndrome ou entidade de doença claramente identificada.

\section{Problemas e oportunidades}

Há uma necessidade urgente de caracterizar e definir a síndrome pós-COVID-19 antes de se compreender o papel do diagnóstico. Possíveis aspectos a serem quantificados e monitorados incluem alterações sustentadas na imunidade inata e adaptativa, efeitos no sistema nervoso, anormalidades de trombose e função endotelial e outros processos subjacentes a manifestações orgânicas específicas prolongadas. Deve-se ter cuidado para evitar preconceitos contra mulheres, pacientes com menos de 40 e com mais de 70 anos, nos quais os testes de anticorpos podem não ser tão sensíveis quanto em outros grupos.

\section{Caminho proposto a seguir}

A síndrome pós-COVID-19 ocorre em muitos grupos diferentes de pacientes, tais como os hospitalizados com doença COVID-19 de gravidade variável, os que não foram hospitalizados ou os que se recuperaram de uma doença aguda pouco sintomática ou assintomática. Um esquema é proposto na Figura 1. 
Figura 1. Descrição abrangente da síndrome pós-COVID-19

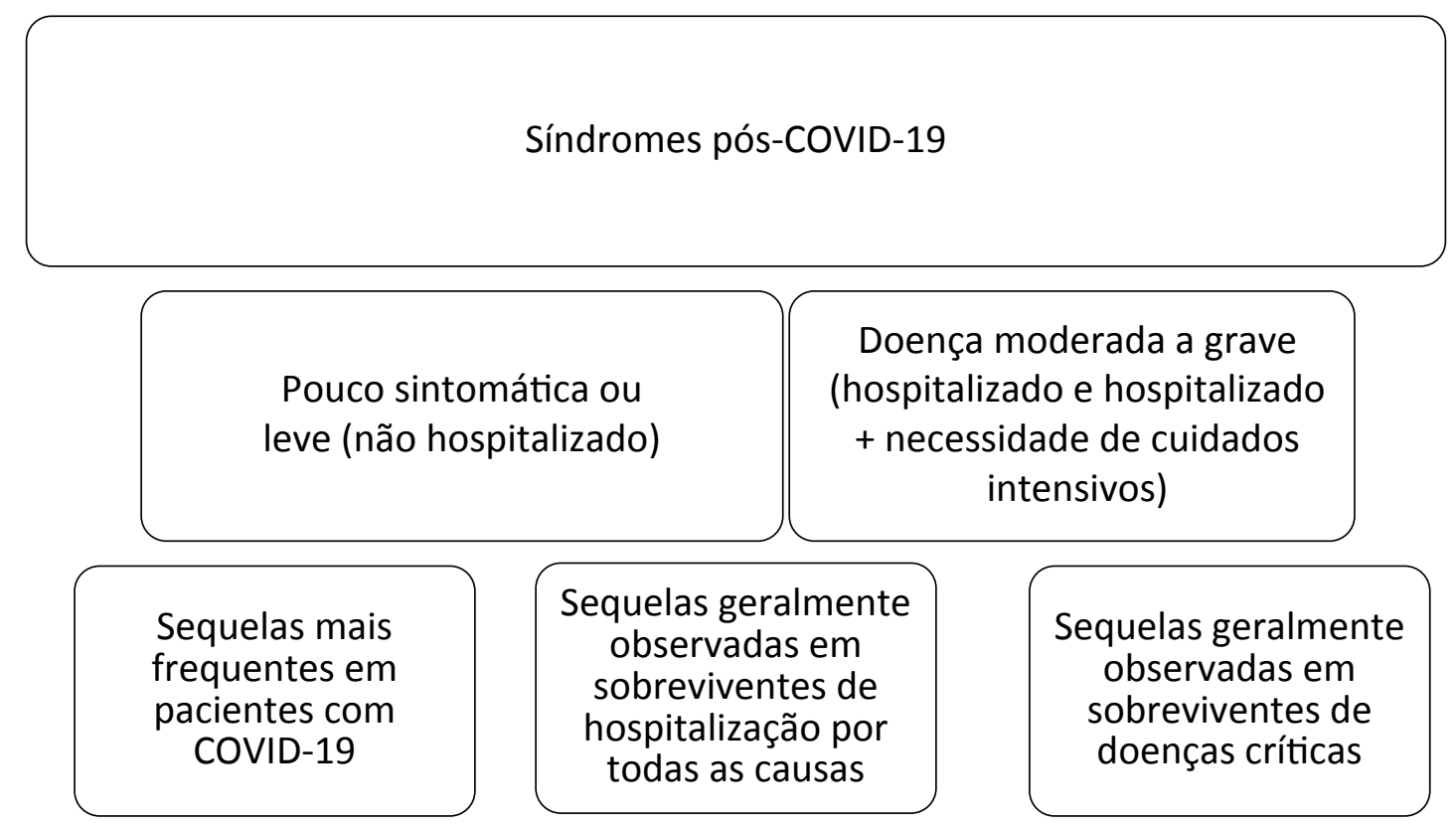

Parece haver pelo menos dois conceitos de doença que se sobrepõem incluídos na síndrome pósCOVID-19. O primeiro são as sequelas prolongadas em pacientes com doença grave - por exemplo, SPTI (relacionado ao suporte de UTI e intervenções relacionadas) e a lesão subjacente de órgãos que tornou a doença tão grave. O segundo é uma doença pós-COVID-19 prolongada que surge desproporcionalmente em pacientes cuja doença inicial era assintomática, leve ou nem mesmo diagnosticada/testada e envolve múltiplas manifestações, as mais comuns das quais são fadiga, mal-estar pós-esforço e disfunção cognitiva. Notou-se que essa apresentação frequentemente gera sintomas persistentes ou recidivantes. Os pacientes, em geral, também têm a maioria de seus exames clínicos relatados como normais. Muitos pacientes deste segundo grupo também apresentam disfunção autonômica significativa e fadiga pós-viral. Existem outros fenótipos em potencial, incluindo indivíduos com sintomas respiratórios (tosse, falta de ar), cognitivos, sensóriomotores, gastrointestinais, renais, dermatológicos, reprodutivos ou cardíacos. A maioria dos pacientes terá envolvimento em várias dessas categorias.

A história natural da COVID-19 e suas consequências e sequelas a longo prazo associadas estão apenas começando a ser desvendadas, embora haja precedentes de síndromes de mal-estar pósviral relatados já em 1891, após a chamada gripe russa. Conforme destacado na Nature, já em 11 de agosto de 2020, um teste COVID-19 negativo não significa que houve recuperação. Provavelmente, a definição de "recuperação" deve incluir duração (por exemplo, um ano sem sintomas é igual à recuperação?), gravidade e flutuação dos sintomas, bem como funcionalidade e qualidade de vida.

Todo aquele que é sintomático permaneceria um "caso" até que cumprisse os critérios de recuperação ou viesse a falecer. Consequentemente, uma limitação importante para a pesquisa e para o desenvolvimento de orientações clínicas é a ausência de uma definição de caso e de uma terminologia homogênea. Além disso, a não resolução da infecção aguda/índice pode estar subjacente a algumas das sequelas tardias. Uma definição poderia permitir a diferenciação entre as sequelas persistentes após a fase aguda da COVID-19 e a síndrome pós-COVID-19, correspondendo ao novo início dos sintomas em um período de semanas a meses após uma aparente recuperação da COVID-19 aguda inicial.

Ver Anexo 4 para obter mais detalhes sobre as discussões do Grupo de Trabalho 2. 


\section{Relatório do Grupo de Trabalho 3. Prevenção, manejo e pesquisa}

Coencarregados: Professora Charu Kaushic, Dra. Silvia Bertagnolio. Ver Anexo 2 para todos os membros do painel.

\section{Resumo}

Foi reconhecido que muitas das evidências disponíveis são apenas referentes a pacientes hospitalizados com COVID-19, que é um grupo relevante, mas não completamente representativo de toda a população afetada pela síndrome pós-COVID-19. Os pacientes com COVID-19 que foram tratados na atenção primária, e mesmo as pessoas que não foram diagnosticadas, muitas vezes estão lidando com serviço ambulatorial que continua sem saber que os sintomas da síndrome pósCOVID-19 não necessariamente se correlacionam com a gravidade do quadro inicial da infecção. A heterogeneidade da síndrome pós-COVID-19 foi um tema de discussão muito repetido. O grupo também reconheceu que a síndrome pós-COVID-19 compartilha sintomas com a encefalomielite miálgica (EM) [também conhecida como síndrome da fadiga crônica (SFC)]. A prevalência da síndrome pós-COVID-19 varia de 10\%-65\% dos indivíduos com infecção primária por SARS-CoV-2 em diversas situações clínicas, mas há ausência de definições e descrições universais. As dúvidas em relação a uma definição da síndrome pós-COVID-19 ser baseada ou não em sintomas devem incluir a evolução ao longo do tempo para o desenvolvimento dos sintomas ou incluir exceções à definição que precisariam de uma discussão mais aprofundada.

\section{Problemas e oportunidades}

Foi repetido que o UK-CDR/GloPID-R Tracker mostrou que menos de 1\% (45 de 5.000 ou mais) dos estudos de pesquisa COVID-19 em andamento se concentram especificamente na síndrome pósCOVID-19 (ou suas terminologias associadas); e a maioria desses estudos segue exclusivamente pacientes hospitalizados, e não aqueles originalmente diagnosticados com sintomas leves ou nunca diagnosticados.

As organizações de pacientes estão solicitando que aprendamos com as experiências adquiridas com a EM/SFC e com outros surtos virais anteriores, como o SARS e o MERS, e que envolvamos pacientes e grupos de pacientes. Seu lema é "Nada sobre nós, sem nós". Um representante de pacientes da África do Sul enfatizou a necessidade de incluir pacientes ambulatoriais com doença leve ou mesmo pacientes pouco sintomáticos em quaisquer novos estudos.

\section{Caminho proposto a seguir}

Existem várias oportunidades para avançar nosso conhecimento por meio da pesquisa. Foi destacada a necessidade de desenvolvimento de um conjunto de desfechos básicos pós-COVID-19 para ensaios clínicos. Novos estudos com mais de uma intervenção/medicamento e em toda a gama de gravidade dos sintomas desenvolvidos durante infecções agudas por COVID-19 podem ser uma via importante para o desenvolvimento de abordagens preventivas. Além disso, a ocorrência de pós-COVID-19 pode ser pesquisada por meio de acompanhamento estendido dos estudos existentes. Por fim, devido a problemas de tamanho da amostra, pode haver necessidade de reunir dados de vários ensaios para possivelmente detectar um efeito de proteção/risco de qualquer agente.

A pesquisa biomédica é necessária para elucidar a fisiopatologia subjacente aos sintomas para o desenvolvimento de esquemas de tratamento adequados e efetivos. Várias hipóteses (incluindo, mas não se limitando a disfunção endotelial, neuroinflamação e desregulação imunológica) estão sendo atualmente levadas em consideração. Os modelos animais de COVID-19 podem ser úteis para avaliar a história natural da pós-COVID-19 e sugerir novos objetivos de medicamentos para 
prevenir ou minimizar essa doença crônica. Muitos dos mecanismos e a patogênese subjacente poderiam ser estudados mais facilmente em modelos animais.

Mais pesquisas sobre a atenção primária e nas unidades de atenção primária à saúde devem ser o ponto focal, tendo em vista que muitos desses pacientes não terão acesso aos cuidados nos níveis secundário/terciário, especialmente nos PBMRs. A maioria dos pacientes com síndrome pós-COVID-19 recebeu tratamento para a infecção aguda por médicos de família. No futuro, os médicos de família provavelmente tratarão as síndromes pós-COVID-19 na maioria dos países. É necessário preencher a lacuna entre a pesquisa/medicina acadêmica e clínica, para que os médicos de família estejam na melhor posição possível para prestar os cuidados adequados. A pesquisa deve dar ênfase aos marginalizados e às populações em desvantagem social ou econômica, tais como prisioneiros, migrantes e refugiados. A pesquisa sobre a prevenção de infecções agudas por COVID-19 e síndrome pós-COVID-19 deve ser explorada para evitar que a COVID-19 complique as desvantagens existentes.

As intervenções não farmacológicas, como a reabilitação física, também devem ser exploradas em todos os níveis do sistema de saúde. Em geral, devem ser estabelecidas a integração e a coordenação dos cuidados para evitar uma dicotomia entre a atenção primária e os cuidados especializados. Será importante haver uma sequência gradativa de cuidados. Uma forte conclamação desse grupo foi para que houvesse cobertura de saúde abrangente e universal para todos os afetados pela COVID-19, com o tema "ninguém deve ser deixado para trás".

Pesquisas adicionais sobre os preditores da síndrome pós-COVID-19 fornecerão novas evidências sobre os fatores de proteção/risco e sobre a influência das doenças crônicas e do estado basal de saúde, não apenas no diagnóstico e nos cuidados físicos, mas também nos aspectos psicológicos e sociais dos cuidados. Todas as avaliações devem ser registradas, para que as trajetórias e os tempos possam ser quantificados. O estudo dos determinantes dos efeitos de longo prazo e a análise dos preditores de quem vai se curar e quem vai desenvolver a pós-COVID-19 deve ajudar a determinar quando iniciar a terapia e o manejo precoces e quem deve entrar nas vias de tratamento estendido. Os profissionais de saúde seriam um grupo valioso de sujeitos para estudos a fim de mensurar a incidência da COVID-19 e os determinantes da síndrome pós-COVID-19.

Os pesquisadores devem compreender a variedade ou heterogeneidade dos sintomas com avaliações físicas, exames de imagem, biomarcadores e um grande número de testes diagnósticos. Em especial, a avaliação cognitiva e outros testes quantitativos devem ser realizados na fase inicial, quando os pacientes receberem alta hospitalar ou forem atendidos na atenção primária. Devem ser usados protocolos padronizados na pesquisa.

Uma nova ferramenta recém-lançada neste webinar e disponível gratuitamente é o recémdesenvolvido CRF da síndrome pós-COVID-19 da OMS. Ele deve se tornar muito útil para compartilhamento e harmonização de dados. Devem ser facilitadas coortes prospectivas com dados em nível de paciente e meta-análises prospectivas dos efeitos terapêuticos do tratamento precoce na prevenção da síndrome pós-COVID-19. O compartilhamento digital de dados por profissionais de saúde, pacientes e público já está disponível por meio de aplicativos e servidores com coleta e análise padronizada de dados. Por exemplo é um registro conduzido pelo paciente baseado na internet e um aplicativo de rastreamento de sintomas. Devemos ter em mente que, até o momento, a maioria dos estudos publicados são muito pequenos, curtos e locais; e seu foco tende a ser em apenas um órgão/sistema. A compreensão de fontes de dados heterogêneas e sua correta interpretação é um objetivo essencial.

Também deve ser explorada a inteligência artificial (IA) aplicada em avaliações realizadas em tempo real. Os esforços para contornar os obstáculos legais existentes em relação ao compartilhamento de dados obtidos em diferentes jurisdições devem ser simplificados com o objetivo de um uso mais 
eficaz de todas as fontes clínicas disponíveis. Uma abordagem promissora seria expandir o trabalho em modelos de previsão para cobrir pacientes ambulatoriais tratados na atenção primária.

Há pesquisadores no Reino Unido que iniciaram testes de desafio em humanos nos quais eles infectam ativamente indivíduos com doses crescentes de SARS-CoV-2 para identificar limiares para induzir infecção. (24) Muitas lacunas no entendimento da síndrome pós-COVID-19 podem ser abordadas por meio desses estudos. (25)

Ver Anexo 5 para obter mais informações sobre as deliberações do Grupo de Trabalho 3. 


\section{Referências}

1. Clinical management of COVID-19 \{website]. Geneva: World Health Organization; 2021 (https:// www.who.int/teams/health-care-readiness-clinical-unit/covid-19, accessed 12 April 2021).

2. Honigsbaum M, Krishnan L. Taking pandemic sequelae seriously: from the Russian influenza to COVID-19 long-haulers. Lancet. 2020;396:1389-91. doi: 10.1016/S0140-6736(20)32134-6.

3. Parra B, Lizarazo J, Jiménez-Arango JA, Zea-Vera AF, González-Manrique G, Vargas J et al. Guillain-Barré syndrome associated with Zika virus infection in Colombia. N Engl J Med. 2016;375:1513-23. doi: 10.1056/NEJMoa1605564.

4. Needham DM, Davidson J, Cohen H, Hopkins RO, Weinert C, Wunsch H et al. Improving longterm outcomes after discharge from intensive care unit. Crit Care Med. 2012;40:502-9. doi: 10.1097/ccm.0b013e318232da75.

5. Needham DM, Dinglas VD, Morris PE, Jackson JC, Hough CL, Mendez-Tellez PA et al. Physical and cognitive performance of patients with acute lung injury 1 year after initial trophic versus full enteral feeding. EDEN trial follow-up. Am J Respir Crit Care Med. 2013;188:567-76. doi: 10.1164/rccm.201304-06510C.

6. Nikayin S, Rabiee A, Hashem MD, Huang M, Bienvenu OJ, Turnbull AE et al. Anxiety symptoms in survivors of critical illness: a systematic review and meta-analysis. Gen Hosp Psychiatry. 2016;43:23-9. doi: 10.1016/j.genhosppsych.2016.08.005.

7. Neufeld KJ, Leoutsakos J-MS, Yan H, Lin S, Zabinski JS, Dinglas VD et al. Fatigue symptoms during the first year following ARDS. Chest. 2020;158:999-1007. doi: 10.1016/j. chest.2020.03.059.

8. Dowdy DW, Eid MP, Dennison CR, Mendez-Tellez PA, Herridge MS, Guallar E et al. Quality of life after acute respiratory distress syndrome: a meta-analysis. Intensive Care Med. 2006;32:111524. doi: 10.1007/s00134-006-0217-3.

9. Dowdy DW, Eid MP, Sedrakyan A, Mendez-Tellez PA, Pronovost PJ, Herridge MS et al. Quality of life in adult survivors of critical illness: a systematic review of the literature. Intensive Care Med. 2005;31:611-20. doi: 10.1007/s00134-005-2592-6.

10. Kamdar BB, Suri R, Suchyta MR, Digrande KF, Sherwood KD, Colantuoni E et al. Return to work after critical illness: a systematic review and meta-analysis. Thorax. 2020;75:17-27. doi: 10.1136/thoraxjnl-2019-213803.

11. Kamdar BB, Sepulveda KA, Chong A, Lord RK, Dinglas VD, Mendez-Tellez PA et al. Return to work and lost earnings after acute respiratory distress syndrome: a 5-year prospective, longitudinal study of long-term survivors. Thorax. 2018;73:125-33. doi: 10.1136/ thoraxjnl-2017-210217.

12. Semler MW, Bernard GR, Aaron SD, Angus DC, Biros MH, Brower RG et al. Identifying clinical research priorities in adult pulmonary and critical care: NHLBI Working Group Report. Am J Respir Crit Care Med. 2020;202:511-23. doi: 10.1164/rccm.201908-1595WS.

13. Mikkelsen ME, Still M, Anderson BJ, Bienvenu OJ, Brodsky MB, Brummel N et al. Society of Critical Care Medicine's International Consensus Conference on Prediction and Identification of Long-Term Impairments After Critical IIIness. Crit Care Med. 2020;48:1670-9. doi: 10.1097/ ccm.0000000000004586.

14. Spruit MA, Holland AE, Singh SJ, Tonia T, Wilson KC, Troosters T. COVID-19: interim guidance on rehabilitation in the hospital and post-hospital phase from a European Respiratory Society and American Thoracic Society-coordinated International Task Force. Eur Respir. 2020;56:2002197. doi: 10.1183/13993003.02197-2020.

15. Needham DM, Sepulveda KA, Dinglas VD, Chessare CM, Friedman LA, Bingham CO, 3rd et al. Core outcome measures for clinical research in acute respiratory failure survivors. An 
International Modified Delphi Consensus Study. Am J Respir Crit Care Med. 2017;196:1122-30. doi: 10.1164/rccm.201702-03720C.

16. Norton A, Olliaro P, Sigfrid L, Carson G, Hastie C, Kaushic C et al. Long COVID: tackling a multifaceted condition requires a multidisciplinary approach. Lancet Infect Dis. 2021:S14733099(21)00043-8. doi: 10.1016/S1473-3099(21)00043-8.

17. Altmann DM, Boyton RJ. Decoding the unknowns in long COVID. BMJ. 2021:n132. doi: 10.1136/bmj.n132.

18. Dennis A, Wamil M, Kapur S, Alberts J, Badley AD, Decker GA et al. Multi-organ impairment in low-risk individuals with long COVID. medRxiv. 2020:2020.10.14.20212555. doi: 10.1101/2020.10.14.20212555.

19. PREVAIL III Study Group, Sneller MC, Reilly C, Badio M, Bishop RJ, Eghrari AO et al. A longitudinal study of Ebola sequelae in Liberia. New Engl J Med. 2019;380:924-34. doi: 10.1056/NEJMoa1805435.

20. Teo T-H, Chan Y-H, Lee WWL, Lum F-M, Amrun SN, Her Z et al. Fingolimod treatment abrogates chikungunya virus-induced arthralgia. Sci Transl Med. 2017;9:eaal1333. doi: 10.1126/ scitransImed.aal1333.

21. Davis HE, Assaf GS, McCorkell L, Wei H, Low RJ, Re'em Y et al. Characterizing Long COVID in an international cohort: 7 months of symptoms and their impact. Cold Spring Harbor Laboratory; 2020 (http://dx.doi.org/10.1101/2020.12.24.20248802).

22. Huang $C$, Huang L, Wang Y, Li X, Ren L, Gu X et al. 6-month consequences of COVID-19 in patients discharged from hospital: a cohort study. Lancet. 2021;397:220-32. doi: 10.1016/ s0140-6736(20)32656-8.

23. Venturelli S, Benatti SV, Casati M, Binda F, Zuglian G, Imeri G et al. Surviving COVID-19 in Bergamo province: a post-acute outpatient re-evaluation. Epidemiol Infect. 2021;149:e32-e. doi: 10.1017/S0950268821000145.

24. Nguyen LC, Bakerlee CW, McKelvey TG, Rose SM, Norman AJ, Joseph N et al. Evaluating use cases for human challenge trials in accelerating SARS-CoV-2 vaccine development. Clin Infect Dis. 2021;72:710-5. doi: 10.1093/cid/ciaa935.

25. Grady C, Shah S, Miller F, Danis M, Nicolini M, Ochoa J et al. So much at stake: ethical tradeoffs in accelerating SARSCoV-2 vaccine development. Vaccine. 2020;38:6381-7. doi: 10.1016/j. vaccine.2020.08.017. 


\section{Expandir nossa compreensão da síndrome pós-COVID-19, primeiro webinar, 9 de fevereiro de 2021, 13hCET}

\begin{tabular}{|c|c|c|}
\hline HORÁRIO & TÓPICO & ORADORES \\
\hline \multicolumn{3}{|l|}{ Sessão Plenária } \\
\hline $13 h-13 h 10$ & Boas-vindas & $\begin{array}{l}\text { Dr. Tedros Adhanom Ghebreyesus } \\
\text { Diretor-Geral, OMS }\end{array}$ \\
\hline \multicolumn{3}{|c|}{ Sessão 1. Síndrome pós-COVID-19: definição do cenário e lições aprendidas } \\
\hline $13 h-13 h 20$ & Discurso de abertura & $\begin{array}{l}\text { Dra. Maria Van Kerkhove } \\
\text { Doenças Emergentes e Zoonoses, OMS }\end{array}$ \\
\hline $13 h 20-13 h 30$ & $\begin{array}{l}\text { Aprender com as infecções virais } \\
\text { anteriores: SARS, MERS, gripe e zika }\end{array}$ & $\begin{array}{l}\text { Dr. Carlos A Pardo-Villamizar } \\
\text { Centro de Mielite e Mielopatia Johns } \\
\text { Hopkins, Divisão de Neuroimunologia } \\
\text { e Infecções Neurológicas; Neurologia } \\
\text { Clínica Avançada, Escola de Medicina da } \\
\text { Universidade Johns Hopkins, EUA. }\end{array}$ \\
\hline $13 h 30-13 h 40$ & $\begin{array}{l}\text { Aprender com doenças críticas anteriores: } \\
\text { síndrome pós-terapia intensiva }\end{array}$ & $\begin{array}{l}\text { Professor Dale M Needham } \\
\text { Professor das Escolas de Medicina (SOM) } \\
\text { e Enfermagem, Grupo de Desfechos } \\
\text { após Cirurgia e Doença Crítica (OACIS); } \\
\text { Departamento de Medicina Física } \\
\text { e Reabilitação, Divisão de Medicina } \\
\text { Pulmonar e Terapia Intensiva, SOM; } \\
\text { Diretor Médico, Programa de Medicina } \\
\text { Física e Reabilitação de Terapia Intensiva; } \\
\text { Universidade Johns Hopkins, EUA }\end{array}$ \\
\hline $13 h 40-13 h 50$ & $\begin{array}{l}\text { Aprendizagem do Workshop do National } \\
\text { Institutes of Health (NIH) sobre sequelas } \\
\text { pós-agudas da COVID-19 (3-4 de } \\
\text { dezembro de 2020) }\end{array}$ & $\begin{array}{l}\text { Dra. Andrea Lerner } \\
\text { Agente Médico, Escritório Imediato do } \\
\text { Diretor, Instituto Nacional de Alergia e } \\
\text { Doenças Infecciosas (NIAID), Institutos } \\
\text { Nacionais de Saúde, EUA. }\end{array}$ \\
\hline $13 h 50-14 h 00$ & $\begin{array}{l}\text { Aprendizagem da reunião do grupo de } \\
\text { suporte ISARIC-GloPID-R-Long COVID: } \\
\text { Fórum sobre a COVID longa (9 a } 10 \text { de } \\
\text { dezembro de 2020) }\end{array}$ & $\begin{array}{l}\text { Dra. Gail Carson } \\
\text { Diretora de Desenvolvimento de Rede } \\
\text { ISARIC, Secretariado GloPID-R, Reino } \\
\text { Unido }\end{array}$ \\
\hline $14 h-14 h 10$ & $\begin{array}{l}\text { Fisiopatologia/imunologia: mecanismos } \\
\text { potenciais }\end{array}$ & $\begin{array}{l}\text { Professor Daniel Altmann } \\
\text { Departamento de Imunologia e } \\
\text { Inflamação, Imperial College London, } \\
\text { Reino Unido. }\end{array}$ \\
\hline $14 h 10-14 h 20$ & $\begin{array}{l}\text { OMS: esforços para avançar nossa } \\
\text { compreensão da síndrome pós-COVID-19 }\end{array}$ & $\begin{array}{l}\text { Dra. Janet Diaz } \\
\text { Prontidão para cuidados de saúde, OMS }\end{array}$ \\
\hline $14 h 20-14 h 30$ & Intervalo & \\
\hline \multicolumn{3}{|c|}{ Sessão 2. Observações sobre a síndrome pós-COVID-19: o que sabemos } \\
\hline $14 h 30-14 h 40$ & $\begin{array}{l}\text { Experiências globais de pesquisa: } \\
\text { Pesquisa conduzida por paciente } \\
\text { COVID-19 }\end{array}$ & $\begin{array}{l}\text { Sra. Hannah Davis } \\
\text { Patient Led-Research Collaborative, } \\
\text { University of London, Reino Unido. }\end{array}$ \\
\hline
\end{tabular}




\begin{tabular}{|c|c|c|}
\hline $14 h 40-14 h 50$ & Experiências da China & $\begin{array}{l}\text { Dr. Bin Cao } \\
\text { Vice-presidente do Hospital da Amizade } \\
\text { China-Japão, Diretor do Departamento de } \\
\text { Medicina Pulmonar e de Terapia Intensiva, } \\
\text { Hospital da Amizade China-Japão, China. }\end{array}$ \\
\hline $14 h 50-15 h$ & Experiências da Itália & $\begin{array}{l}\text { Dr. Marco Rizzi } \\
\text { Unidade Principal de Doenças Infecciosas, } \\
\text { Hospital Papa Giovanni XXIII, Bérgamo, } \\
\text { Itália. } \\
\text { Dr. Simone Piva } \\
\text { Departamento de Especialidades Médicas } \\
\text { e Cirúrgicas, Ciências Radiológicas e } \\
\text { Saúde Pública, Universidade de Brescia; } \\
\text { Departamento de Anestesia, Cuidados } \\
\text { Críticos e Emergências, Hospital } \\
\text { Universitário Spedali Civili, Brescia, Itália. }\end{array}$ \\
\hline $15 h-15 h 10$ & Experiências do Brasil & $\begin{array}{l}\text { Dr. Regis Goulart Rosa } \\
\text { Médico intensivista e pesquisador de } \\
\text { desfechos pós-UTI do Hospital Moinhos } \\
\text { de Vento, Porto Alegre, Brasil. }\end{array}$ \\
\hline 15h10-15h20 & Experiências da Índia & $\begin{array}{l}\text { Professora Shinjini Bhatnagar } \\
\text { Chefe, Instituto de Ciência e Tecnologia } \\
\text { de Saúde Materna e Infantil Translacional, } \\
\text { NCR Biotech Science Cluster, Faridabad, } \\
\text { Índia }\end{array}$ \\
\hline 15h20-15h30 & Intervalo & \\
\hline \multicolumn{3}{|c|}{$\begin{array}{l}\text { Sessão 3. Grupos de trabalho para desenvolvimento de uma definição de caso clínico e lacunas/ } \\
\text { métodos de pesquisa }\end{array}$} \\
\hline 15h30-16h45 & $\begin{array}{l}\text { Grupo de Trabalho 1: desenvolvimento de } \\
\text { uma definição de caso clínico } \\
\text { O painel descreverá o seguinte: } \\
\text { - Clusters clínicos de sinais ou sintomas } \\
\text { (fenótipos) } \\
\text { - Existe uma evolução ao longo do tempo } \\
\text { para incluir na definição? } \\
\text { - As complicações, como acidente vas- } \\
\text { cular cerebral, síndrome coronariana } \\
\text { aguda, embolia pulmonar, síndrome de } \\
\text { Guillain-Barré, fazem parte da síndrome } \\
\text { pós-COVID-19? } \\
\text { Como ligar a mecanismos } \\
\text { fisiopatológicos } \\
\text { Questões e métodos de pesquisa } \\
\text { prioritários }\end{array}$ & $\begin{array}{l}\text { Encarregado: Professora Margaret } \\
\text { Herridge } \\
\text { Professora de Medicina, } \\
\text { Cientista Sênior em Cuidados Críticos e } \\
\text { Medicina Respiratória, Diretor de Pesquisa } \\
\text { em Cuidados Críticos da Universidade } \\
\text { de Toronto; Diretor Clínico do Programa } \\
\text { RECOVER } \\
\text { Programa Grace RECOVER para Doenças } \\
\text { Crônicas Crônicas; Colíder, Canadian } \\
\text { COVID-19 Prospective Cohort Study } \\
\text { (CANCOV) University Health Network, } \\
\text { Toronto, Canadá }\end{array}$ \\
\hline
\end{tabular}




\begin{tabular}{|c|c|c|}
\hline 15h30-16h45 & $\begin{array}{l}\text { Grupo de Trabalho 2: desenvolvimento de } \\
\text { uma definição de caso clínico; papel do } \\
\text { diagnóstico } \\
\text { - Como incluir diagnósticos virais (sorolo- } \\
\text { gia, rAG, PCR) } \\
\text { - Como incluir testes imunológicos, infla- } \\
\text { matórios, metabólicos e de coagulação } \\
\text { - Como incluir exames de imagem } \\
\text { - Como incluir ferramentas/escalas de } \\
\text { avaliação padronizadas } \\
\text { - Como ligar a mecanismos } \\
\text { fisiopatológicos }\end{array}$ & $\begin{array}{l}\text { Encarregado: Professor John Marshall } \\
\text { Professor de Cirurgia da Universidade } \\
\text { de Toronto, cirurgião de traumas e } \\
\text { intensivista do Hospital St Michael, }\end{array}$ \\
\hline 15h30-16h45 & $\begin{array}{l}\text { Grupo de Trabalho 3: prevenção, manejo e } \\
\text { pesquisa } \\
\text { - Quais intervenções farmacológicas } \\
\text { podem ser levadas em consideração? } \\
\text { Quais são os objetivos em potencial? } \\
\text { - Quais intervenções não farmacológicas } \\
\text { devem ser levadas em consideração? } \\
\text { Intervenções ao nível do paciente? Inter- } \\
\text { venções ao nível do sistema de saúde? } \\
\text { - Prioridades de pesquisa - Como os } \\
\text { estudos devem avaliar os desfechos de } \\
\text { longo prazo? } \\
\text { - Quais abordagens podem ser usadas } \\
\text { para coletar dados padronizados e } \\
\text { análises? }\end{array}$ & $\begin{array}{l}\text { Encarregado: Professora Charu Kaushic } \\
\text { Diretora Científica do Instituto de Infecção } \\
\text { e Imunidade dos Institutos Canadenses } \\
\text { de Pesquisa em Saúde (CIHR); Presidente } \\
\text { da GloPID-R (Colaboração de Pesquisa } \\
\text { Global para Preparação para Doenças } \\
\text { Infecciosas); Departamento de Patologia } \\
\text { e Medicina Molecular, Universidade } \\
\text { McMaster, Canadá. }\end{array}$ \\
\hline 16h45-17h & $\begin{array}{l}\text { Elaboração de relatório de grupos de } \\
\text { trabalho }\end{array}$ & Membros do painel e encarregados \\
\hline $17 h-17 h 30$ & Relatório dos três grupos de trabalho & Encarregados \\
\hline 17h30-17h35 & $\begin{array}{l}\text { Síndrome pós-COVID-19: uma perspectiva } \\
\text { de emergência de saúde e considerações } \\
\text { finais }\end{array}$ & $\begin{array}{l}\text { Dr. Mike Ryan } \\
\text { Preparação e Resposta a Emergências de } \\
\text { Saúde, OMS }\end{array}$ \\
\hline
\end{tabular}




\section{Membros do painel: Grupo de Trabalho 1}

\section{Encarregado: Professora Margaret Herridge}

Professora de Medicina, Cientista Sênior, Cuidados Críticos e Medicina Respiratória, Diretora de Pesquisa em Cuidados Críticos da Universidade de Toronto. Diretora, Programa RECOVER, Diretora Clínica, Programa Grace RECOVER para Doenças Crônicas Críticas. Colíder: Canadian COVID-19 Prospective Cohort Study (CANCOV) University Health Network, Toronto, Canadá.

\section{Dr. Nisreen A Alwan}

Professor Associado em Saúde Pública, Universidade de Southampton, Reino Unido. Defensor de pacientes COVID-19.

\section{Professora Shinjini Bhatnagar}

Chefe, Saúde Materna e Infantil, Instituto de Ciência e Tecnologia de Saúde Translacional, Índia.

\section{Professor Bin Cao}

Vice-presidente do Hospital da Amizade China-Japão, Diretor do Departamento de Medicina Pulmonar e de Terapia Intensiva, Hospital da Amizade China-Japão, China.

\section{Sra. Hannah Davis}

Patient Led-Research Collaborative, Universidade de Londres, Reino Unido.

\section{Professor Dale M Needham}

Professor das Escolas de Medicina (SOM) e Enfermagem, Grupo de Desfechos Após Doença Crítica e Cirurgia (OACIS). Departamento de Medicina Física e Reabilitação, Divisão de Medicina Pulmonar e de Terapia Intensiva, SOM. Diretor Médico, Programa de Reabilitação e Medicina Física de Cuidados Críticos, Universidade Johns Hopkins, EUA.

\section{Professor Christopher G Chute}

Universidade Johns Hopkins, médico-cientista e informático biomédico conhecido por terminologias biomédicas e padrões de tecnologia da informação em saúde (CID-11).

\section{Professor Francesco Landi}

Departamento de Geriatria, Fondazione Policlinico Universitario Agostino Gemelli, Roma. Desde abril, instituiu um serviço ambulatorial pós-agudo para indivíduos que receberam alta após recuperação da COVID-19.

\section{Dr. Daniel Munblit}

Conferencista Honorário Sênior, Imperial College London, Reino Unido. Professor, Departamento de Pediatria e Doenças Infecciosas Pediátricas, Universidade Sechenov, Moscou, Federação Russa. Líder da Coorte StopCOVID da Rede Hospitalar Sechenov.

\section{Sr. Juno Simorangkir}

Fundador do COVID Survivor Indonesia.

\section{Dr. Liam Townsend}

Departamento de Doenças Infecciosas, Hospital St James, Dublin, Irlanda.

\section{Professor Rolf-Detlef Treede}

Neurociências e fisiologia, dor crônica, CID-11. Mannheim Center for Translational Neuroscience (MCTN), Mannheim, Alemanha. 


\section{Dra. Andrea Lerner}

Agente Médica, Escritório Imediato do Diretor, Instituto Nacional de Alergia e Doenças Infecciosas (NIAID), Institutos Nacionais de Saúde, EUA.

\section{Sharon Saydah}

Cientista Sênior, Diretora de Gerenciamento de Cientistas dos Centros de Controle e Prevenção de Doenças (CDC), EUA. Lidera a Equipe de História Natural da Força-Tarefa de Epidemiologia de Resposta à COVID-19 do CDC.

\section{Dr. Ettore Beghi}

Departamento de Neurociência, Istituto di Ricerche Farmacologiche Mario Negri IRCCS, Milão, Itália.

\section{Professor Daniel Altmann}

Departamento de Imunologia e Inflamação, Imperial College London, Reino Unido.

\section{Dr. Jose Luis Ayuso-Mateos}

Presidente do Departamento de Psiquiatria e Diretor do Centro Colaborador da OMS para Pesquisa e Treinamento em Serviços de Saúde Mental da Universidad Autónoma de Madrid. Chefe do Departamento de Psiquiatria do Hospital Universitario de la Princesa, Madri, Espanha.

\section{Carlos Pardo-Villamizar}

Centro de Mielite e Mielopatia Johns Hopkins, Divisão de Neuroimunologia e Infecções Neurológicas; Neurologia Clínica Avançada, Escola de Medicina da Universidade Johns Hopkins, EUA.

\section{Secretariado da OMS \\ Dr. Tarun Dua: coencarregado \\ Dra. Carine Alsokhn \\ Dr. Fahmy Hanna \\ Dr. Robert Jakob \\ Dr. Jacobus Preller \\ Dr. Pryanka Relan}

\section{Membros do painel: Grupo de Trabalho 2}

\section{Encarregado: Professor John Marshall}

Professor de Cirurgia da Universidade de Toronto, cirurgião de traumas e intensivista do Hospital St Michael, Universidade de Toronto, Canadá.

\section{Professora Djillali Annane}

Reitora da Escola de Medicina Simone Veil da Université Paris Saclay-UVSQ; Diretora do Departamento Geral de UTI, Hospital Raymond Poincaré, França.

\section{Professor Nigel Curtis}

Chefe de Doenças Infecciosas Pediátricas, Royal Children's Hospital Melbourne e Murdoch Children's Research Institute, Parkville, Austrália.

\section{Dra. Anne Von Gottberg}

Instituto Nacional de Doenças Transmissíveis, Centro de Doenças Respiratórias e Meningite, África do Sul.

\section{Professora Beverley Hunt}

Professora de Trombose e Hemostasia, King's College London, Reino Unido. 


\section{Dra. Nathalie MacDermott}

Doenças Infecciosas Pediátricas, King's College London, Reino Unido. Sobrevivente de COVID-19.

\section{Dr. Piero Olliaro}

Professor de Doenças Infecciosas Relacionadas à Pobreza, Centro de Medicina Tropical e Saúde Global, Departamento de Medicina de Nuffield, Universidade de Oxford.

\section{Dr. Marco Rizzi}

Unidade Principal de Doenças Infecciosas, Hospital Papa Giovanni XXIII, Bérgamo, Itália.

\section{Professor Manu Shankar-Hari}

Cientista Clínico e Professor de Medicina de Cuidados Críticos do NIHR, Guy's and St Thomas' Hospital NHS Foundation Trust, Londres, Reino Unido.

\section{Dr. Regis Goulart Rosa}

Médico intensivista e pesquisador de desfechos pós-UTI do Hospital Moinhos de Vento, Porto Alegre, Brasil.

\section{Sra. Elizabeth Semper}

Presidente da associação: COVID persistente España.

\section{Professor Yaseen Arabi}

Presidente do Departamento de Terapia Intensiva; Diretor Médico, Serviços Respiratórios; Professor, Faculdade de Medicina, Universidade Rei Saud Bin Abdulaziz de Ciências da Saúde, Arábia Saudita.

\section{Dra. Ivana Blazic}

Radiologista certificada com doutorado em Radiologia, subespecializada em Oncologia. Atualmente, ocupa o cargo de chefe de seção de ressonância magnética do Clinical Hospital Center Zemun em Belgrado, Sérvia.

\section{Secretariado da OMS \\ Maria Rosario Pérez: copresidente \\ Dr. Robert Jakob \\ Dr. Mark Perkins \\ Dra. Nicoline Schiess \\ Dra. Archana Seahwag \\ Dra. Maaya Kita Sugai \\ Dra. Anna Thorson}

\section{Membros do painel: Grupo de Trabalho 3}

\section{Encarregada: Professora Charu Kaushic}

Diretora Científica do Instituto de Infecção e Imunidade dos Institutos Canadenses de Pesquisa em Saúde (CIHR); Presidente da GloPID-R (Colaboração de Pesquisa Global para Preparação para Doenças Infecciosas); Departamento de Patologia e Medicina Molecular, Universidade McMaster, Canadá.

\section{Dr. Oved Amitay}

Presidente e CEO da Solve M.E., uma organização nacional de destaque sem fins lucrativos exclusivamente dedicada a resolver a encefalomielite miálgica (anteriormente conhecida como síndrome da fadiga crônica).

\section{Dr. Francesco Castelli}

Professor de Doenças Infecciosas; Chefe da Divisão de Medicina Infecciosa e Tropical da Universidade de Brescia e ASST Spedali Civili de Brescia, Itália. 


\section{Sra. Sarah Geline}

Apoio à COVID longa: África do Sul.

\section{Dra. Laura Gochicoa}

Pneumologista Pediátrico, Chefe do Departamento de Fisiologia Respiratória, INER, Cidade do México, México.

\section{Professora Yee Sin Leo}

Especialista em doenças infecciosas em adultos, Diretor-Executivo do Centro Nacional de Doenças Infecciosas, Cingapura.

\section{Professor Andrea Fiorillo}

Professor de Psiquiatria da Universidade da Campânia Luigi Vanvitelli, Caserta, Itália. Professor Associado, Segunda Universidade de Nápoles, Itália.

\section{Professor Jose Luis Peñalvo}

Saúde Pública, Instituto de Medicina Tropical, Antuérpia, Bélgica. Professor Adjunto de Epidemiologia, Friedman School of Nutrition Science and Policy na Tufts University, Boston, EUA.

\section{Dra. Simone Piva}

Departamento de Especialidades Médicas e Cirúrgicas, Ciências Radiológicas e Saúde Pública, Universidade de Brescia; Departamento de Anestesia, Cuidados Críticos e Emergências, Hospital Universitário Spedali Civili, Brescia, Itália.

\section{Dra. Nathalie Strub-Wourgaft}

Diretor de Doenças Tropicais Negligenciadas, Iniciativa de Medicamentos para Doenças Negligenciadas (DNDi), Genebra, Suíça.

\section{Dr. Miroslav Zvolsky}

Classificações de saúde, coleta de dados de saúde (registros nacionais de saúde, dados administrativos, DRG, codificação CID).

\section{Dra. Lori Newman}

Médica NIAID, NIH Infectious Diseases, EUA. Desde fevereiro de 2020 faz parte da equipe de resposta do NIH à COVID-19 nas áreas de sequelas pós-agudas, sorologia e revisão de propostas de ensaios clínicos de epidemiologia, terapêutica, vacinas e diagnósticos.

\section{Dra. Saniya Sabzwari}

Professora associada de medicina familiar na Aga Khan University, Karachi, Paquistão

\section{Professor Alessandro Padovani}

Unidade de Neurologia, Departamento de Ciências Clínicas e Experimentais, Universidade de Brescia, Brescia, Itália. Impacto neurológico em pacientes com COVID-19.

\section{Colaboradores da OMS}

Dra. Silvia Bertagnolio: coencarregada

Dra. Neerja Chowdhary

Dr. Wouter D Groute

Dr. Robert Jakob

Dra. Marie Pierre Preziosi

Dra. Joan B Soriano 


\section{Anexo 3. Desenvolvimento de uma definição de caso clínico para a síndrome pós- COVID-19 (deliberações adicionais do Grupo de Trabalho 1)}

Desenvolvimento de uma definição de caso: há uma necessidade imediata de ir além da contagem de casos para priorizar a intervenção e pesquisas adicionais, e uma necessidade de registros clínicos de pacientes. As definições de caso podem incorporar uma caracterização detalhada e o gerenciamento de itens acionáveis. Para prevenir a variabilidade na precisão e na confiabilidade da apuração de casos, devem ser elaborados e adotados critérios pragmáticos claros.

Provavelmente haverá necessidade de diferentes definições de caso. Por exemplo, para o caso de uso de advocacia do paciente, pode ser necessário ser mais inclusivo (mais sensível), para permitir que os indivíduos tenham acesso a suporte e benefícios e garantir que todos com sintomas sejam incluídos, independentemente da confirmação da COVID-19. Por outro lado, as definições de vigilância e pesquisa podem exigir critérios mais rígidos, como infecção por SARS-CoV-2 confirmada em laboratório.

Os casos de uso a serem levados em consideração incluem:

- advocacia: definição mais ampla, incluindo autorrelatos;

- clínica: definição ampla, baseada em dados clínicos e autorrelatos;

- vigilância: definição ampla, baseada em CID e outras codificações;

- pesquisa: definição mais estrita, baseada em diagnósticos "definitivos".

Compreender os fenótipos: os fenótipos podem ser identificados por meio de registros eletrônicos (EHR) e de grandes conjuntos de dados administrativos que permitem a caracterização clínica detalhada, o destino de alta e tratamento, a utilização de cuidados de saúde e a determinação das trajetórias dos desfechos ao longo do tempo. O uso dessas fontes de dados, no entanto, depende de procedimentos de validação. Há conjuntos de dados preexistentes/históricos e pesquisas mais recentes (por exemplo, a pesquisa do Reino Unido com 2.500 pacientes não hospitalizados) que podem ser informativos, mas as fontes de viés devem ser levadas em consideração. Os dados fenotípicos precisam ser mais bem informados por meio da biologia/genética translacional em diversas populações de pacientes e situações geográficas e do sistema de saúde.

Mais estudos são necessários sobre os clusters de sintomas. Alguns clusters de sintomas podem estar focados em sistemas de órgãos separados e distintos, ao passo que outros podem envolver vários sistemas de órgãos ou se manifestar apenas como sintomas sistêmicos.

A gravidade da doença, as comorbidades preexistentes e os tratamentos associados podem gerar riscos, modificar ou confundir os desfechos relatados usando um modelo com base em sintomas ou sistemas. Os pacientes com COVID-19 criticamente enfermos com síndrome do desconforto respiratório agudo complicado (SDRA) podem manifestar muitos sintomas condizentes com SPTI. Dado o desenvolvimento frequente de disfunção de múltiplos órgãos e a necessidade de cuidados críticos complexos, pode ser difícil delinear quais sintomas/disfunções de órgãos pós-COVID-19 são especificamente atribuíveis à COVID-19. É importante notar a natureza recorrente da doença na maioria das pessoas que a vivenciam; e isso pode até fazer parte de uma definição. Embora possa ser descoberta uma única etiologia que dê origem a uma doença multissistêmica variável, deve-se usar uma abordagem holística para simplificar os cuidados. Os pacientes não devem ser encaminhados unicamente para cuidados de especialistas. Ver a Tabela 3A. 1 no tocante a considerações para agrupamentos fenotípicos. 
Tabela 3A.1 Fenótipos por sistema de órgãos e fisiopatologia

\begin{tabular}{|c|c|}
\hline Fenótipo por sistema de órgãos & Fenótipo por fisiopatologia \\
\hline $\begin{array}{l}\text { - } \text { sintomas sistêmicos (fadiga etc.) } \\
\text { - } \text { neurológicos } \\
\text { - } \text { disfunção cognitiva/perda de memória } \\
\text { - } \text { respiratórios } \\
\text { - cardiovasculares } \\
\text { - musculoesqueléticos } \\
\text { - metabólicos } \\
\text { - gastrointestinais } \\
\text { - dermatológicos } \\
\text { - } \text { alérgicos e imunológicos } \\
\text { - outros }\end{array}$ & $\begin{array}{l}\text { - inflamação } \\
\text { - desregulação do subconjunto imunológico } \\
\text { - } \text { autoimune } \\
\text { - } \text { coagulação/vasculopatia } \\
\text { - } \text { perseverança viral/infecção de longo prazo } \\
\text { - endócrinos/metabólicos. }\end{array}$ \\
\hline
\end{tabular}

Definir uma evolução ao longo do tempo para a definição do caso: não houve consenso sobre a evolução ao longo do tempo. Houve um claro consenso de que apenas sintomas/disfunções orgânicas novas pós-doença aguda devem ser incluídos na evolução ao longo do tempo da definição.

Alguns tempos sugeridos incluem:

- curto prazo: um ponto do tempo precoce pós-infecção aguda de quatro a oito semanas;

- médio prazo: um ponto do tempo tardio pós-infecção aguda de dois a seis meses;

- longo prazo: sintomas que duram mais de seis meses.

Não está claro se deveria haver um ponto do tempo limítrofe externo para inclusão como síndrome pós-COVID-19 ou qual seria especificamente o ponto do tempo final.

Uma documentação gradativa da infecção viral inicial e da doença inicial é essencial para o uso de informações sobre a evolução ao longo do tempo (ver também CRF da OMS de 8/9 de fevereiro de 2021). Isso deve incluir o seguinte.

- nível de evidência para infecção viral: nenhum, antígeno, RNA, anticorpos;

- gravidade da doença: nenhuma, leve, moderada, grave, crítica;

- nível de evidência para gravidade da doença: autorrelato, dados clínicos.

Lacunas e metodologia de pesquisa: há uma oportunidade única, no início da investigação dessa síndrome, para alinhamento e coordenação de esforços. Deve ser encorajada uma colaboração multinacional, multidisciplinar e centrada no paciente, e também o desenvolvimento e a adoção de conjuntos de dados centrais de consenso para caracterizar a doença aguda e um acompanhamento estruturado/cronometrado. Pode ser necessário desenvolver um conjunto de desfechos básicos na síndrome pós-COVID-19 para permitir a harmonização dos dados e posterior meta-análise dos dados. Deve-se chegar a um consenso sobre o que deve ser mensurado e como os desfechos devem ser medidos. As prioridades de pesquisa sugeridas incluem:

- Fenótipo: examinar coortes multinacionais de megadados/sistemas de saúde/EHR/enquetes solicitadas/ambidirecionais (prospectivas e retrospectivas) para elucidar fenótipos clínicos robustos por meio de sintomas/sistemas de órgãos ou mecanismo fisiopatológico; garantir a inclusão de populações vulneráveis/frágeis; investigar controles não infectados para excluir comorbidades randômicas. Será importante incluir as seguintes populações: crianças, gestantes e lactantes/recém-nascidos, pacientes hospitalizados e não hospitalizados, todas as geografias, grupos socialmente desfavorecidos, origens étnicas. 
- Mecanismo: avaliação científica básica (multiômica/genética)/translacional/fisiopatológica de sintomas propostos/fenótipos de sistemas de órgãos; e trabalho translacional aninhado de coortes ambidirecionais.

- Outros: fenotipagem imunológica e biomarcadores, exames de imagem, prevenção/ reabilitação/dor crônica (multimodalidade incluindo saúde física/neurocognitiva/mental), desfechos de saúde do cuidador familiar como modificação de risco.

O Grupo de Trabalho 1 reconheceu os vários nomes e definições em uso nas arenas acadêmica e leiga para descrever a síndrome pós-COVID-19, dos quais o grupo deve estar ciente, e a necessidade de coordenação e harmonização globais. Nesse estágio, o grupo não foi capaz de chegar a uma definição consensual da síndrome pós-COVID-19 para ser usada em todos as situações e em todos os pacientes. Dado que novas evidências estão sendo produzidas, as definições serão revisadas periodicamente. Esse pode ser considerado um resultado para os próximos webinars/encontros.

Tabela 3A.2 Nomes sugeridos na literatura relacionados à síndrome pós-COVID-19

\begin{tabular}{|c|c|}
\hline Nome & Referência \\
\hline Síndrome da COVID crônica & Baig AM. Med Virol. 2020, 23 de outubro. Doi: 10.1002/jmv.26624 \\
\hline Sequelas tardias da COVID-19 & Site do CDC (acessado em 12 de abril de 2021) \\
\hline CovID longa & Mahase E. BMJ. 14 de julho de 2020; 370: m2815 \\
\hline COVID longa & $\begin{array}{l}\text { Perego E, et al. Wellcome Open Research (editorial). 2020; 5: 224; The } \\
\text { Royal Society }\end{array}$ \\
\hline COVID longa & $\begin{array}{l}\text { Nature (editorial) (Let patients help define long-lasting COVID symptoms) } \\
8 \text { de outubro de 2020; Long COVID Forum 9-10 de dezembro de } 2020 \text { do } \\
\text { ISARIC/GloPID-R/Long COVID Support; Lancet (editorial) (Facing up to } \\
\text { Long COVID) } 12 \text { de dezembro de } 2020\end{array}$ \\
\hline COVID de longa duração & $\begin{array}{l}\text { Nath A. Long-Haul COVID. Neurology. } 29 \text { de setembro de 2020; } 95 \text { (13): } \\
\text { 559-560. Scientific American (Carolyn Barber, } 29 \text { de dezembro de 2020) }\end{array}$ \\
\hline COVID-19 de longo prazo & Uma edição especial do Journal of Clinical Medicine (ISSN 2077-0383) \\
\hline Sequelas pós-agudas & $\mathrm{NIH}$ \\
\hline Síndrome pós-COVID & Site do NHS (acessado em 12 de abril de 2021) \\
\hline COVID-19 pós-agudo & Vários artigos em: BMJ, Eur J Phys Rehabil Med, Eur J Intern Med \\
\hline Síndrome pós-COVID-19 & $\begin{array}{l}\text { A OMS sugere o uso do termo síndrome pós-CoVID-19, pois é neutro e } \\
\text { não tem atribuição de causalidade, e já tem um código CID-10 designado } \\
\text { como U09.9 Uso emergencial de códigos CID para o surto da doença da } \\
\text { COVID-19 (acessado em } 12 \text { de abril de 2020) }\end{array}$ \\
\hline
\end{tabular}


- Fadiga pós-viral ou síndrome da fadiga crônica, doença de intolerância ao esforço sistêmico (SEID), também conhecida como encefalomielite miálgica'.

- Sintomas que persistem além de quatro semanas após o início dos sintomas sugestivos de COVID-19².

- Estão sendo relatados sintomas de múltiplos órgãos após COVID-19 por um número crescente de pacientes. Eles variam de tosse e falta de ar a fadiga, dor de cabeça, palpitações, dor no peito, dor nas articulações, limitações físicas, depressão e insônia, e afetam pessoas de várias idades. Na conferência da Lancet-Chinese Academy of Medical Sciences, realizada em 23 de novembro de 2020, Bin Cao apresentou dados (no prelo, Lancet) sobre as consequências de longo prazo da COVID-19 em pacientes de Wuhan, e alertou que podem persistir disfunções e complicações em alguns pacientes que receberam alta, durante pelo menos seis meses. A assim chamada COVID longa é uma preocupação crescente em saúde, sendo necessária agora uma ação para resolvê-la ${ }^{3}$.

- Sinais e sintomas que se desenvolvem durante ou após uma infecção condizente com COVID-19 continuam por mais de 12 semanas e não são explicados por um diagnóstico alternativo4.

- Indivíduos cujos sintomas persistem ou se desenvolvem fora da infecção viral inicial, mas a duração e a patogênese são desconhecidas 5 .

- Início de episódios persistentes ou recorrentes de um ou mais dos seguintes sintomas, dentro de $x^{\star}$ semanas de infecção por SARS-CoV-2 e que continuam por $y^{\star}$ semanas ou mais ${ }^{6}$.

Já existem várias definições sugeridas para a síndrome pós-COVID-19, propostas por várias sociedades e autores, listadas na Tabela A3.3. Nesse estágio, não podemos chegar a uma definição de consenso da síndrome pós-COVID-19 para ser usada em todos as situações e em todos os pacientes. Dado que novas evidências estão sendo produzidas, as definições serão revisadas periodicamente. Esse pode ser considerado um resultado para os próximos webinars/encontros.

Komaroff AL. Advances in understanding the pathophysiology of Chronic Fatigue Syndrome. JAMA. 2019 Jul 5. doi: 10.1001/jama.2019.8312. PMID: 31276153.

2 Perego E, Callard F, Stras L, Melville-Jóhannesson B, Pope R, Alwan NA. Why the patient-made term 'Long COVID' is needed. Wellcome Open Research. 2020:5:224.

3 Facing up to long COVID (editorial). Lancet. 2020;396(10266):1861. doi: 10.1016/S0140-6736(20)32662-3.

4 NICE guideline [NG188] COVID-19 rapid guideline: managing the long-term effects of COVID-19. 18 December 2020.

5 Barber C. The problem of 'Long Haul COVID'. Scientific American. 29 December 2020 (https://www.scientificamerican. com/article/the-problem-of-long-haul-covid/?print=true, accessed 12 April 2021).

6 Long COVID: what is it, and what is needed? (editorial). The Royal Society. 23 October 2020. 


\section{Anexo 4. Papel do diagnóstico no manejo clínico - deliberações adicionais do Grupo de Trabalho 2}

Há inúmeras estratégias possíveis de testagem diagnóstica que orientam o atendimento clínico e o prognóstico. Essas estratégias são importantes para pacientes, profissionais de saúde e sistemas de saúde. O teste diagnóstico deve levar em conta: a persistência da infecção viral; o envolvimento de múltiplos órgãos/sistemas; as alterações crônicas no sistema imunológico; o papel dos testes de triagem de alta sensibilidade no envolvimento multissistêmico; e provavelmente outros. O diagnóstico ajuda a resolver questões de patogênese, diagnóstico e novos tratamentos em potencial. No contexto da COVID-19, é aconselhável ver os diagnósticos de três perspectivas diferentes: testes que são importantes do ponto de vista da saúde pública; os que são necessários para o cuidado individual de um paciente; e aqueles para pesquisa - todos os quais podem se sobrepor uns aos outros.

Fisiopatologia: até o momento, muitas dúvidas permanecem sobre a fisiopatologia e que não são necessariamente mutuamente exclusivas. Elas incluem:

- De que modo o vírus e o hospedeiro interagem (incluindo genética e resposta imunológica)?

- O transtorno está associado à persistência do vírus, possivelmente em um reservatório oculto como o trato gastrointestinal (GI) ou focos virais sustentados como, por exemplo, no fígado, na medula óssea, no cérebro ou no coração? Isso leva uma estimulação imunológica contínua e a estudos de mérito sobre antivirais?

- O transtorno é uma consequência de lesão direta do tecido, possivelmente relacionada às interações do SARS-CoV-2 com a ACE-2 e dano epitelial com lesão subsequente do tecido e fibrose ou cicatriz?

- Que papel desempenha a desregulação do sistema renina-angiotensina-aldosterona como consequência da regulação negativa da ACE-2 relacionada à entrada viral?

- Como definir ainda o papel do dano às células endoteliais e da tromboinflamação?

- O transtorno é uma resposta desregulada do hospedeiro (imune ou não) ao vírus (levantando a questão de uma possível base genética ou epigenética para a doença)? Isso pode levar à inflamação crônica? É necessária uma caracterização adicional [ou seja, o papel dos interferons, linfodepleção de células T, citocinas pró-inflamatórias (IL-6, TNF alfa)]?

- Alguns pacientes sofrem de uma consequência da terapia como, por exemplo, os efeitos da ventilação mecânica ou de esteroides?

- Como os fatores culturais e socioeconômicos moldam a doença?

- O transtorno é específico para COVID-19 ou se assemelha a síndromes pós-sepse ou póstrauma?

- A resposta imune é diferente durante a fase aguda da COVID-19, dependendo da gravidade da doença? Essa resposta pode ter protegido os pacientes de doenças graves ou morte; mas essa resposta imune persistiu após a doença aguda e produziu a síndrome pós-COVID-19.

- Quais são os mecanismos subjacentes à causa das manifestações neurológicas (ou seja, neuroinflamação)?

Diagnóstico laboratorial do SARS-COV-2: a confirmação da infecção por SARS-CoV-2 é relevante e inclui o uso de testes de anticorpos. As opções incluem diferentes tipos de imunoglobulina, além de IgG e IgM. É importante confirmar a infecção por meio de testes de anticorpos (com ampliação para diferentes imunoglobulinas); enfatizando que o teste de anticorpos deve ser apropriado para a janela de tempo. Por exemplo, se houver reservatórios no intestino, isso se refletiria na resposta da IgA sérica? Se essa for uma resposta de hipersensibilidade, esperaríamos ver uma grande resposta? Além disso, pode haver alguma variabilidade com base na variante viral envolvida. Em geral, os protocolos e as diretrizes padrão para o teste de SARS-CoV-2 devem orientar as abordagens de teste. Considerações para testes: 
- PCR, papel potencial dos testes de antígenos que são mais específicos e utilidade dos testes sequenciais.

- Soropositividade, título de anticorpos neutralizantes (IgM, IgA, IgE) para avaliar infecção aguda, crônica ou prévia. Observe, no entanto, a baixa sensibilidade e especificidade que podem ser vistas na população em geral, bem como em certas subpopulações (ou seja, mulheres e aqueles com idade inferior a 40 anos e acima de 70 anos).

- Teste genético para variabilidade/suscetibilidade.

Resposta do hospedeiro/lesão de órgão: em relação à resposta do hospedeiro, seria interessante verificar se o hospedeiro foi ou não preparado para responder a uma infecção viral prévia (ou seja, teste de interferon). Os marcadores específicos de lesão de órgão incluem enzimas hepáticas elevadas, creatinina elevada ou presença de hematúria, proteinúria; anormalidades endócrinas (como eixo adrenal, função tireoidiana, níveis de glicose) e a perturbação da cascata de coagulação (como fibrinogênio, dímeros $\mathrm{D}$, anticorpos antifosfolipídeos e marcadores de turnover trombótico e fibrinolítico). Em geral, o teste deve sempre ser conduzido clinicamente.

Marcadores inflamatórios: a inflamação aguda se transforma em inflamação crônica? A inflamação se refere principalmente a uma resposta desregulada do hospedeiro. A inflamação pode sugerir a importância de alterações genéticas e/ou epigenéticas no hospedeiro. Seria importante saber se os pacientes têm níveis circulantes elevados e persistentes de citocinas [como ocorre na pneumonia adquirida na comunidade (PAC)] ou de catecolaminas (como ocorre após sepse ou queimadura). Outras opções incluem testar o sistema nervoso autônomo com exames de rotina não invasivos. Essa é uma área que merece investigação adicional com protocolos de pesquisa padrão.

Modalidades de exames de imagem: várias modalidades estão disponíveis para uso de exames de imagem para ajudar no diagnóstico da síndrome pós-COVID-19. Um exame de imagem convencional pode não revelar anormalidades funcionais graves que só podem ser vistas por ressonância magnética, PET scan ou ecocardiografia. O uso de exames de imagem em pacientes com síndrome pós-COVID-19 deve sempre ser conduzido clinicamente. Ver Tabela A4.1.

Tabela A4.1 Papel potencial do exame de imagem na avaliação da síndrome pós-COVID-19

\begin{tabular}{|c|c|}
\hline Sintoma/fenótipo de sinais pós-COVID-19 & Modalidade de exame de imagem \\
\hline Neurológico/psiquiátrico & $\begin{array}{l}\text { Ressonância magnética do cérebro, ressonância magnética } \\
\text { da coluna, imagens funcionais e técnicas avançadas de } \\
\text { ressonância magnética, imagens híbridas (PET-MRI, PET-CT) }\end{array}$ \\
\hline Cardiovascular & $\begin{array}{l}\text { Ecocardiografia, ressonância magnética cardíaca, } \\
\text { angiografia coronária por TC, angiografia pulmonar por } \\
\text { TC, ultrassom doppler vascular (carótidas, extremidades, } \\
\text { transcraniana), angiografia por TC ou ressonância } \\
\text { magnética }\end{array}$ \\
\hline Pulmonar & TC de tórax, radiografia de tórax, ultrassonografia pulmonar \\
\hline Hepático/renal/gastrointestinal, metabólico & $\begin{array}{l}\text { Ultrassonografia abdominal, tomografia computadorizada } \\
\text { de abdome, ressonância magnética abdominal, medicina } \\
\text { nuclear }\end{array}$ \\
\hline Imunológico/reumatológico & $\begin{array}{l}\text { Diferentes modalidades de exames de imagem de acordo } \\
\text { com a indicação clínica }\end{array}$ \\
\hline Pediátrico & $\begin{array}{l}\text { Diferentes modalidades de exames de imagem; devido ao } \\
\text { risco de radiação, ultrassonografia e ressonância magnética } \\
\text { são opções preferíveis }\end{array}$ \\
\hline Em geral & $\begin{array}{l}\text { Diferentes modalidades de exames de imagem de acordo } \\
\text { com as indicações clínicas }\end{array}$ \\
\hline
\end{tabular}


Testes, escalas e ferramentas padronizados: pode ser necessário avaliar os desfechos mentais mensurados com testes psicológicos e físicos. Essas questões vão além do que poderia ser incluído em uma discussão de grupo de trabalho. Foi fornecida uma lista restrita de possíveis listas ou ferramentas/escalas: qualidade de vida relacionada à saúde (versão EQ-5D, 3L ou 5L; SF-36V2); saúde mental (HADS, IES-R); dor (dor EQ-5D); função cognitiva (cego para MoCA); função física (6MWT); função muscular e nervosa (preensão manual); função pulmonar; e capacidade de exercício. 


\section{Anexo 5. Prevenção, manejo e pesquisa - deliberações adicionais do Grupo de Trabalho}

São apresentadas a seguir as deliberações, por meio de perguntas aos membros do painel.

Pergunta 1: Que elementos devem ser levados em consideração para a pesquisa de intervenções farmacológicas e objetivos em potencial?

- Mais pesquisas são necessárias. De acordo com a ferramenta de rastreamento ISARIC, apenas 45 de 5.000 (menos de 1\%) dos projetos de pesquisa em andamento se concentram na síndrome pós-COVID-19.

- Podem ser realizados ensaios clínicos bem planejados com acompanhamento estruturado. As cinco experiências pós-ensaio brasileiras (I, II, III, IV e VI), relatadas pelo Dr. Regis Goulart Rosa, fornecem um exemplo para o desenho adequado de outros estudos, que podem ser replicados em outros locais ao redor do mundo.

- É difícil conduzir desenhos de estudos com mais de uma intervenção/medicamento; no entanto, estão em andamento ensaios de plataforma em larga escala para COVID-19 aguda e, portanto, estes também podem ser feitos para a síndrome pós-COVID-19.

- Há representantes de pacientes dos PBMRs (África do Sul) solicitando que pacientes ambulatoriais com COVID-19 originalmente leve ou mesmo com COVID-19 pouco sintomática, que agora estejam com síndrome pós-COVID-19, sejam incluídos nos ensaios.

- São recomendados ensaios pragmáticos de medicamentos na atenção primária, uma vez que a maior parte dos pacientes depende de médicos de família/CGs.

- As organizações de pacientes (Solve ME, Patient Led Research e outros) solicitam cada vez mais conhecimento sobre as lições aprendidas com a história sobre SFC/DSIE e pandemias anteriores. Lembre-se também: "Nada sobre nós sem nós".

- Gestão complexa de doenças por sistemas de saúde para populações marginalizadas (por exemplo, prisioneiros, migrantes, refugiados).

\section{Pergunta 2: Quais são as considerações mais importantes sobre as intervenções não} farmacológicas no nível do paciente e no nível do sistema de saúde?

- A reabilitação deve enfocar os aspectos físicos e psicológicos/sociais. Deve-se também cogitar intervenções como Tai-Chi e outras abordagens alternativas e tradicionais para bemestar.

- A identificação de biomarcadores de inflamação (basal e longitudinalmente) associados à síndrome pós-COVID-19 pode ser a chave para prever quem precisa ser incluído no tratamento. Devem ser elaborados estudos para compreender os determinantes (fatores de risco) da síndrome pós-COVID-19. As opções metodológicas incluem o uso de grupos de comparação via EHR ou estudos de base populacional.

- Incluem avaliação cognitiva e planos de manejo desde o início.

- Incluem os efeitos psicológicos e mentais na equipe de saúde, bem como nos pacientes e suas famílias.

- Educação e informação pública são fundamentais.

- A coordenação de um modelo abrangente é fundamental.

- Cobertura universal de saúde - "ninguém é deixado para trás".

Pergunta 3: Como a síndrome pós-COVID-19 pode ser avaliada nos desfechos do estudo?

- Os desfechos em potencial devem incluir combinação de sintomas, avaliações físicas, exames de imagem, biomarcadores e ômicas.

- Podem ser feitas meta-análises prospectivas dos efeitos terapêuticos do tratamento precoce na prevenção da síndrome pós-COVID-19 a partir de estudos já concluídos.

- É necessária uma coleta de dados padronizada. O novo CRF da OMS é muito útil, sendo também necessário um conjunto de desfechos básicos pós-COVID-19. 
- Coordenação do compartilhamento global de dados para responder às perguntas mais rapidamente.

Pergunta 4: Que abordagem deve ser adotada para a coleta e análise padronizada de dados?

- A análise deve identificar os fatores de risco positivos/negativos associados ao desenvolvimento e à gravidade da síndrome pós-COVID-19.

- A meta-análise de vários estudos é um componente-chave para reunir várias fontes de evidência.

- Desenvolver modelos de previsão do desenvolvimento da pós-COVID-19 em pacientes ambulatoriais.

- Cogitar o uso de IA, aplicativos e avaliação em tempo real de EHR; alguns obstáculos legais e éticos existentes devem ser eliminados para o bem público. Usando informações agrupadas de EHR, os modelos podem ser estendidos para captar preditores da atenção primária para hospitalização e, idealmente, acompanhamento após a alta.

- Definições e descrições universais sobre infecção, cura, recuperação e síndrome pósCOVID-19. 


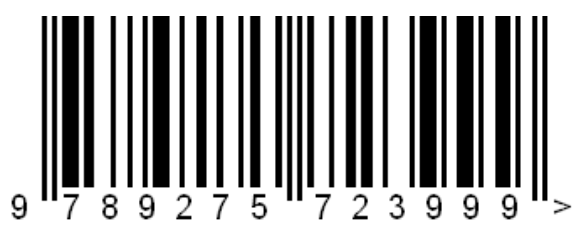

